Revista Española de Antropología Americana

ISSN: 0556-6533

https://doi.org/10.5209/REAA.63701

\title{
La filiación cultural y el simbolismo de los objetos de turquesa en el Templo Mayor de Tenochtitlan
}

\author{
Emiliano R. Melgar Tísoc ${ }^{1}$
}

Recibido: 19 de octubre de 2018 / Aceptado: 24 de octubre de 2018

Resumen. En las ofrendas del Templo Mayor de Tenochtitlan en la Cuenca de México, los mexicas depositaron miles de piezas de turquesas en diferentes ofrendas. Gracias a los análisis de composición no destructivos fue posible determinar que la gran mayoría de las piezas eran turquesas químicas o geológicas del Noroeste de México y del Suroeste de los Estados Unidos. Sin embargo, ¿qué simbolismo tenían los objetos? ¿dónde fueron elaborados y con qué instrumentos y técnicas? Para tratar de resolverlo, en esta investigación se presentan las comparaciones iconográficas de las piezas con códices y esculturas, encontrando que formaban discos de mosaico y ornamentos de determinadas deidades nahuas, y eran parte de la decoración de cuchillos, rostros y cetros. También se aplicaron análisis tecnológicos con arqueología experimental para caracterizar las huellas de manufactura con Microscopía Electrónica de Barrido (MEB). Entre los resultados principales se pudo identificar tres estilos tecnológicos: uno relacionado con los mixtecos, otro que parece tener un origen no mesoamericano y un último que comparte la tecnología del estilo imperial tenochca. Así mismo, se revisaron los mosaicos de turquesa con iconografía Mixteca-Puebla y se encontró que los personajes de las piezas tenochcas difieren en su iconografía, armado y composición.

Palabras clave: turquesa; mexicas; estilo; tecnología; simbolismo.

\section{[en] Cultural Provenance and Symbolism of the Turquoise Objects from the Great Temple of Tenochtitlan}

\begin{abstract}
In the offerings of the Great Temple of Tenochtitlan in the Basin of Mexico, the Aztecs buried thousands of turquoise pieces. The majority of them were inlays assembled in complex mosaics, like disks, ornaments of certain Nahua gods, and parts of chert knives and scepters. With the compositional analysis, I confirmed that almost all of the bluish-stones were chemical or real turquoise from Northwestern Mexico and the American Southwest. But, which was the symbolism of these objects, where they were produced and with which tools and techniques? The aim of this paper is to show the iconographical comparison of the objects with different codex and sculptures, while the technological analysis with experimental archaeology served for the characterization of the manufacturing traces with Scanning Electron Microscopy (SEM). As results, I identified three lapidary styles at Tenochtitlan: one is related with the Mixtecs, another could be non-Mesoamerican, and the last one shares the tools and techniques of the Tenochcan Imperial Style. In addition, I reviewed the Mixteca-Puebla turquoise mosaics and found that the Tenochcan ones were different in the iconography and assemblage of the characters.
\end{abstract}

Keywords: turquoise; Mexica; style; technology; symbolism.

Sumario. 1. Introducción. 2. La identificación de turquesas en Tenochtitlan. 3. La clasificación de las turquesas entre los nahuas. 4. La variedad de objetos de turquesa ofrendados y su simbolismo. 5. La

1 Museo del Templo Mayor, Instituto Nacional de Antropología e Historia, México. melgare@hotmail.com 
elaboración de los objetos de turquesa. 6. El tributo de turquesas y el Templo Mayor. 7. Los mosaicos de turquesa de Tenochtitlan y la tradición Mixteca-Puebla. 8. Conclusiones. 9. Referencias.

Cómo citar: Melgar Tísoc, Emiliano R. 2018. «La filiación cultural y el simbolismo de los objetos de turquesa en el Templo Mayor de Tenochtitlan». Revista Española de Antropología Americana 48: 251-275.

\section{Introducción}

La turquesa fue uno de los materiales pétreos más ampliamente utilizados por distintos grupos de artesanos lapidarios para elaborar ornamentos, destacando la musivaria o arte de hacer mosaicos. Esta manera de confeccionar objetos con teselas de este mineral o su combinación con otras piedras azul-verdosas o de otras tonalidades, e incluso con incrustaciones de otras materias primas, permitió la creación de complejos objetos rituales y/o bienes de prestigio. Además, las propiedades simbólicas otorgadas a los distintos materiales por su origen, color o características visuales, los convirtieron en recursos muy apreciados por las culturas prehispánicas.

Sin embargo, no todos los materiales azules hallados en Mesoamérica son de turquesa, un fosfoaluminato de cobre hidratado, ya que en contextos arqueológicos se han recuperado turquesas verdaderas mezcladas con otras piedras azul-verdosas como crisocola, amazonita, malaquita y azurita. Por ello, Phil Weigand (1993: 300303) propuso llamar «turquesa química» a la verdadera y «turquesa cultural» a los demás minerales que compartían su gama cromática y que fueron utilizados como sustitutos u homónimos de la misma.

En el caso del Templo Mayor de Tenochtitlan, en varias de sus ofrendas se han recuperado cuentas y mosaicos conformados por miles de teselas de tonalidades azules consideradas turquesas (Figura 1). Aunque su origen geológico es ajeno a la Cuenca de México e incluso vienen de fuera de Mesoamérica, ello no implica que todos los objetos hechos en este material exótico sean manufacturas foráneas. En este sentido, el estudio detallado de la turquesa también permite abordar y revisar algunos postulados que existen en torno a este material desde hace varias décadas. Entre ellos tenemos la suposición de que casi todos los mosaicos de turquesa hallados en Mesoamérica fueron hechos por artesanos lapidarios mixtecos (Schávelzon 1980). Ello está relacionado con la idea de que no hay turquesas en Mesoamérica antes del periodo Posclásico o, si las hay, son muy pocas y se presentan de forma aislada en épocas anteriores (Weigand 1993). También existen interpretaciones que contrastan parcialmente con lo anterior al tomar en cuenta su origen geológico norteño (Newell y Gallaga 2004; Gallaga y Melgar 2016; Gallaga 2017), ya que, si se encuentran piezas en contextos mesoamericanos, se postula a priori que su manufactura fue foránea, es decir, que llegaron ya elaboradas desde los lugares de obtención de esta materia prima (López Luján 2006: 187). Incluso cuando se consideran los pocos talleres de turquesa excavados, como Pueblo Bonito en el Cañón del Chaco o Alta Vista en Zacatecas, hay quienes asumen que son los lugares de producción de las piezas recuperadas en sitios mesoamericanos, aun cuando no coincidan cronológicamente (Cobos 1998: 920). Si a ello le aumentamos la obtención de turquesas a través del tributo o del comercio y los cambios que pudo haber en las rutas de circulación de este material a través del tiempo, el panorama se complica enormemente. 

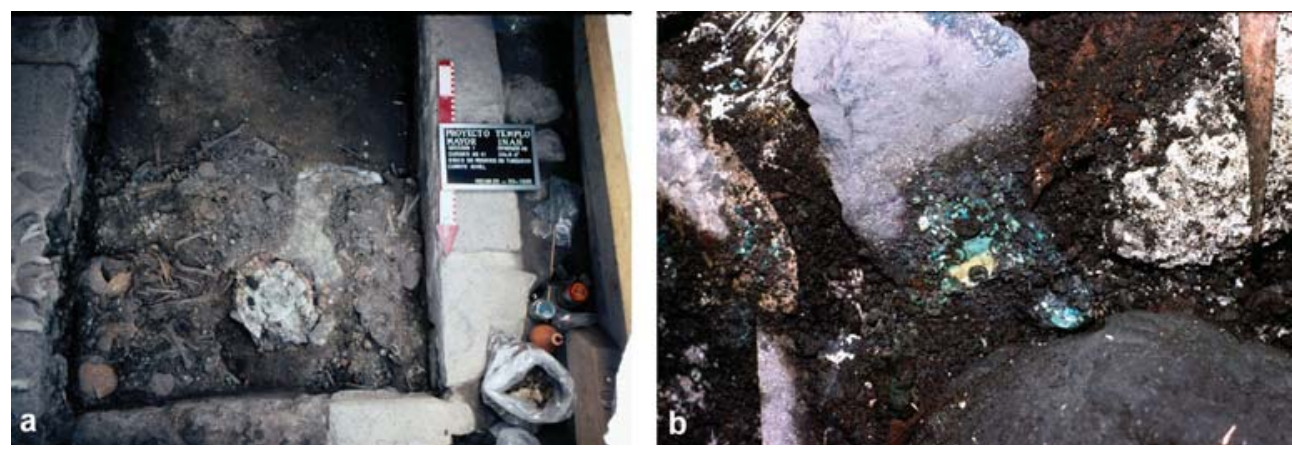

Figura 1. Mosaicos de turquesa hallados en la Ofrenda 48 (a) y la Ofrenda 17 (b) del Templo Mayor de Tenochtitlan. (Cortesía Archivo del Museo del Templo Mayor).

En la valoración de estas consideraciones resulta fundamental comparar las técnicas de manufactura, tanto de los materiales locales donde éstos fueron recuperados, como de aquellos otros donde se supone que podrían haber sido elaborados, como la región de origen geológico de los materiales pétreos. Este proceso está relacionado con factores políticos, ideológicos y económicos que se expresan mediante las preferencias culturales por determinados materiales e instrumentos de trabajo -a expensas de otros- y cuya repetición sistemática hecha por un grupo durante un espacio y tiempo dados, permite adscribirlos a una determinada tradición artesanal y estilo tecnológico (Melgar 2014: 5). La primera se refiere a procesos de trabajo de larga duración y amplitud regional, mientras que el estilo es de menor tiempo y en una escala local, por lo cual se complementan y permiten integrar la combinación de datos culturales y espaciales en diferentes dimensiones temporales (Willey y Phi1lips 1954: 34-39). Así, en el estudio de materiales arqueológicos es importante y necesario considerar el aspecto tecnológico cuando se trata de asignarles filiaciones culturales y temporalidades.

Además, la turquesa ha sido empleada como una de las principales evidencias arqueológicas de la existencia de relaciones de larga distancia entre el Suroeste de los Estados Unidos y Mesoamérica, aunque todavía genera polémica el papel que pudieron desempeñar estos contactos y las vías de comunicación utilizadas (Weigand 1997; Newell y Gallaga 2004; Gallaga y Blainey 2016). El estudio de estas rutas se dificulta al incluir el tributo de este material y la escasez de comparaciones entre los objetos recuperados en Tenochtitlan y los de las provincias tributarias para detectar similitudes o diferencias. Asimismo, falta analizar la relación entre los lugares de producción y la distribución desde un enfoque tecnológico que permita identificar instrumentos de trabajo particulares de cada taller o región y su ausencia en otras áreas. De esta manera sería posible reevaluar el postulado de que casi todos los mosaicos de turquesa hallados en Mesoamérica los produjeron artesanos lapidarios mixtecos.

\section{La identificación de turquesas en Tenochtitlan}

En arqueología es muy importante la correcta identificación del mineral turquesa de otros materiales con tonalidades similares, ya que la distribución geológica de cada 


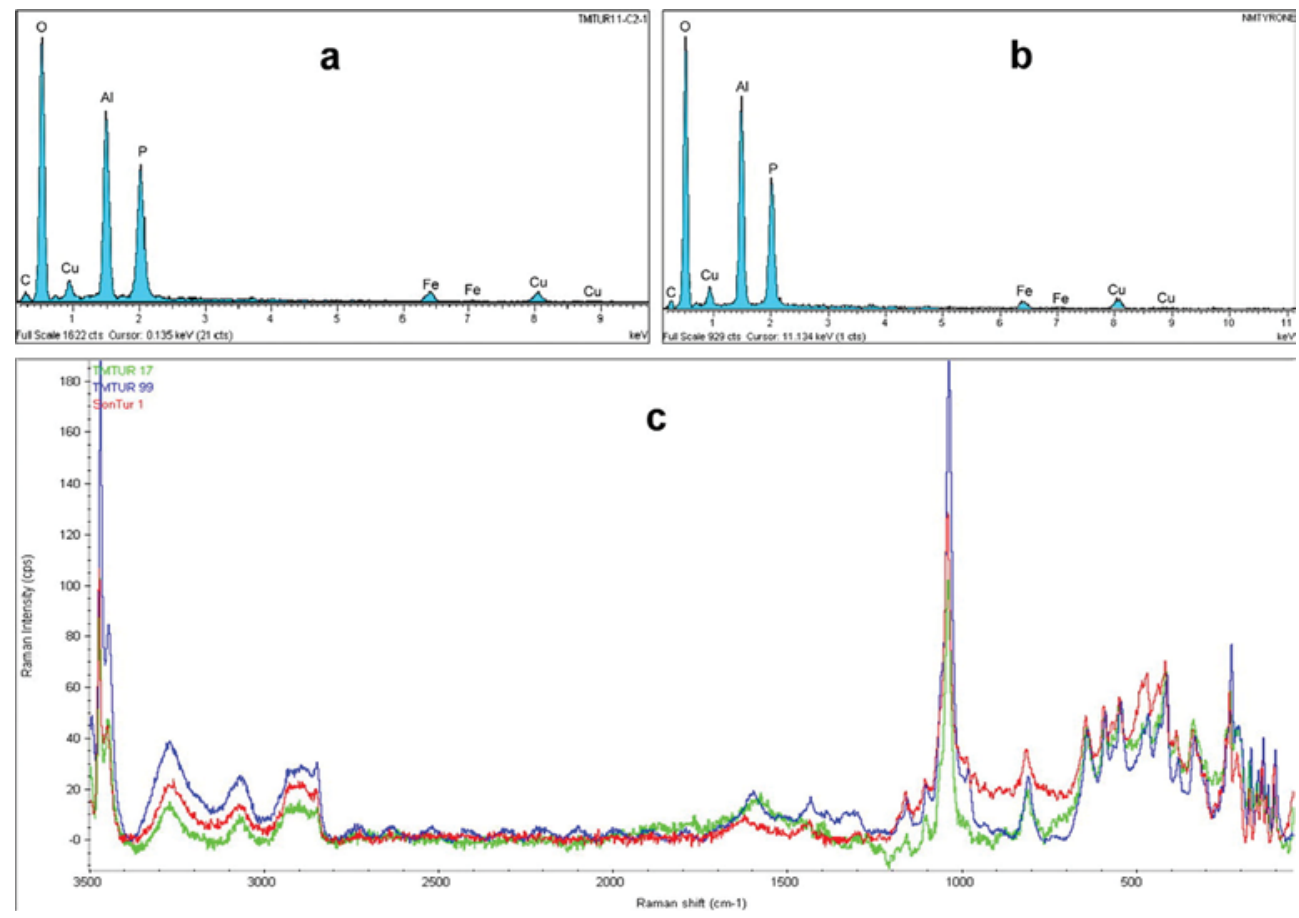

Figura 2. Caracterización mineralógica de las turquesas del Templo Mayor comparadas con muestras geológicas de referencia con EDS (a) y $\mu$ Raman (b). (Espectros elaborados por Emiliano Melgar, Mario Monroy y Cristina Zorrilla).

uno es diferente y el estudio de sus afloramientos permite rastrear sus procedencias o probables zonas de obtención.

Para determinar cuáles son los minerales presentes en las piezas del Templo Mayor y sus probables regiones de origen se realizaron diversos análisis de su composición química elemental y sus compuestos o enlaces moleculares (Figura 2), como Fluorescencia de luz ultravioleta (UVF), Microsonda de Rayos X (EDS), Fluorescencia de Rayos X (XRF) y Espectroscopía Micro-Raman ( $\mu$ Raman). Para confirmar que los minerales modernos de referencia de diversos yacimientos de México y Estados Unidos están bien caracterizados, se realizaron estudios petrográficos y de Difracción de Rayos X con objeto de diferenciar las turquesas de los demás minerales azules. De esta manera fue posible apreciar que casi la totalidad de los objetos de Tenochtitlan analizados resultaron ser turquesas químicas o verdaderas de tonalidades azules y verdes (Figura 3), cuyos yacimientos conocidos se encuentran en el Noroeste de México (Gallaga y Melgar 2016; Gallaga 2017) y en el Suroeste de Estados Unidos (Figura 4). La comparación temporal también permitió detectar que varias de las piezas de las ofrendas más antiguas presentan una menor variabilidad en su composición que las halladas en depósitos posteriores, lo cual implica la obtención de turquesas verdaderas de pocos afloramientos al principio y de una mayor cantidad/ variedad al final, relacionado con las expansiones territoriales (Melgar 2014: 196-210).

A partir de ello se observa una predilección de los tenochcas por adquirir verdaderas turquesas, por lo que su origen foráneo y lejano parece haber sido muy importante. Este interés en las turquesas de zonas desérticas norteñas (Figura 5a) pudiera estar relacionado con cierta oposición simbólica que tienen con las piedras verdes, 
Figura 3. Variedad de colores que presentan las turquesas químicas. (Fotografía de Jonathan Silva).
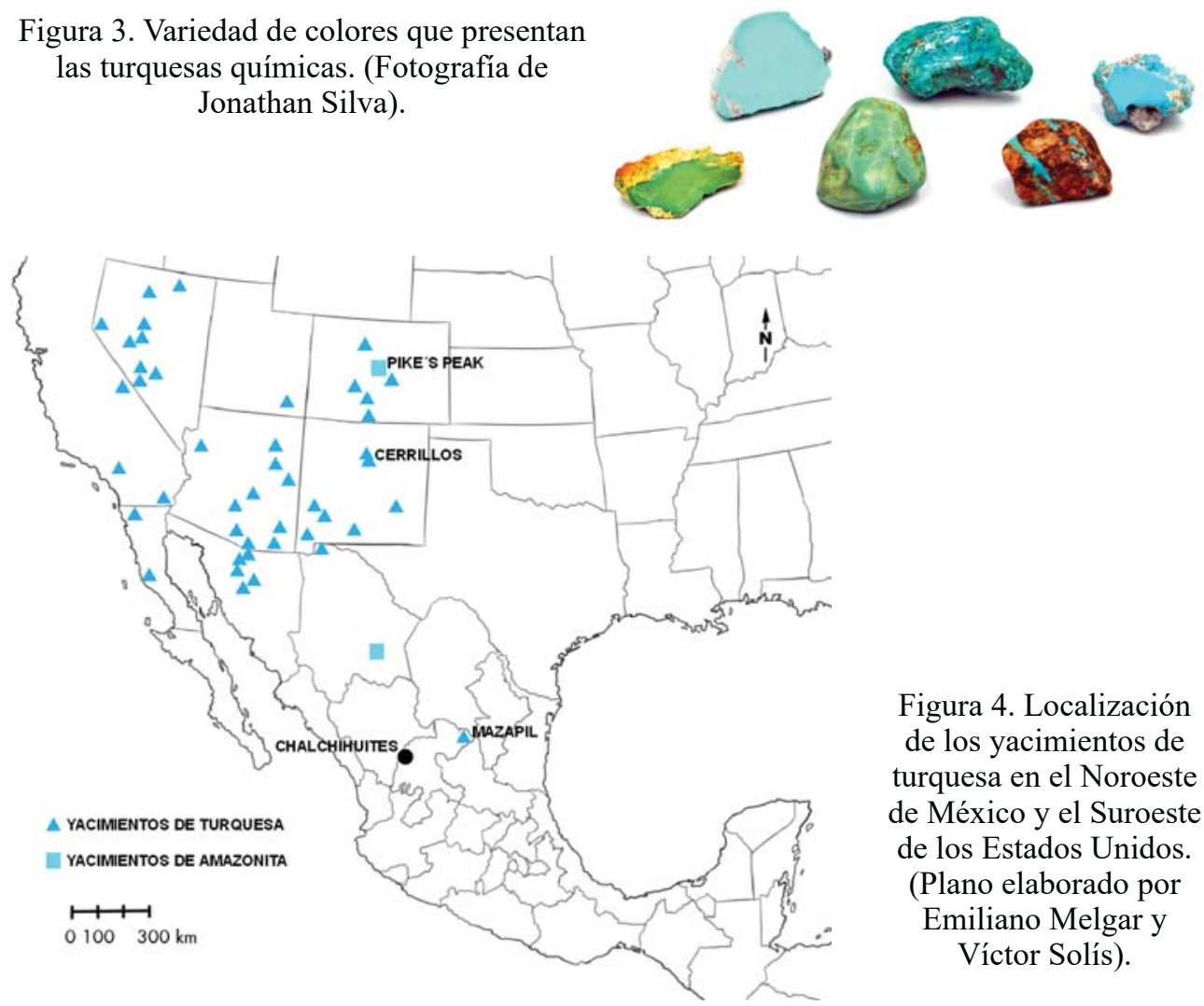

Figura 4. Localización de los yacimientos de turquesa en el Noroeste de México y el Suroeste de los Estados Unidos.

(Plano elaborado por

Emiliano Melgar y Víctor Solís).
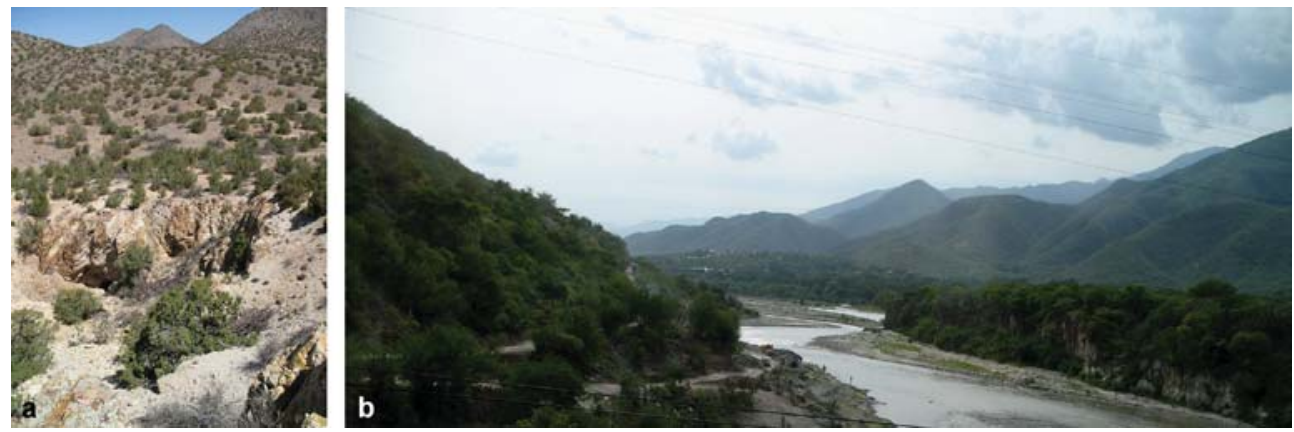

Figura 5. Vistas panorámicas de los entornos donde están las minas de turquesa en la zona desértica de Cerrillos, Nuevo México (a) y el caudaloso valle del Río Motagua, Guatemala, donde están los afloramientos de jadeíta (b). (Fotografías de Emiliano Melgar).

de origen sureño en valles tropicales de ríos caudalosos (Figura 5b). Al respecto, las turquesas aluden al fuego, el linaje, la realeza, el cometa y el año, aunque también tienen la raíz para indicar hierbas y hojas (Cuadro 1). Por su parte, las piedras verdes se vinculan con la lluvia, las deidades pluviales, la fertilidad y las corrientes de agua. Además, la turquesa más valorada fue la de los dioses, llamada teoxíhuitl, la cual era traída de lejos por los teochichimecas, grupos de cazadores que habitaban en los desiertos, montes y cuevas septentrionales (Sahagún 2006, lib. X, cap. XXIX: 582$583)$, y a quienes los nahuas admiraban por ser fuertes, ligeros y rápidos al atravesar 


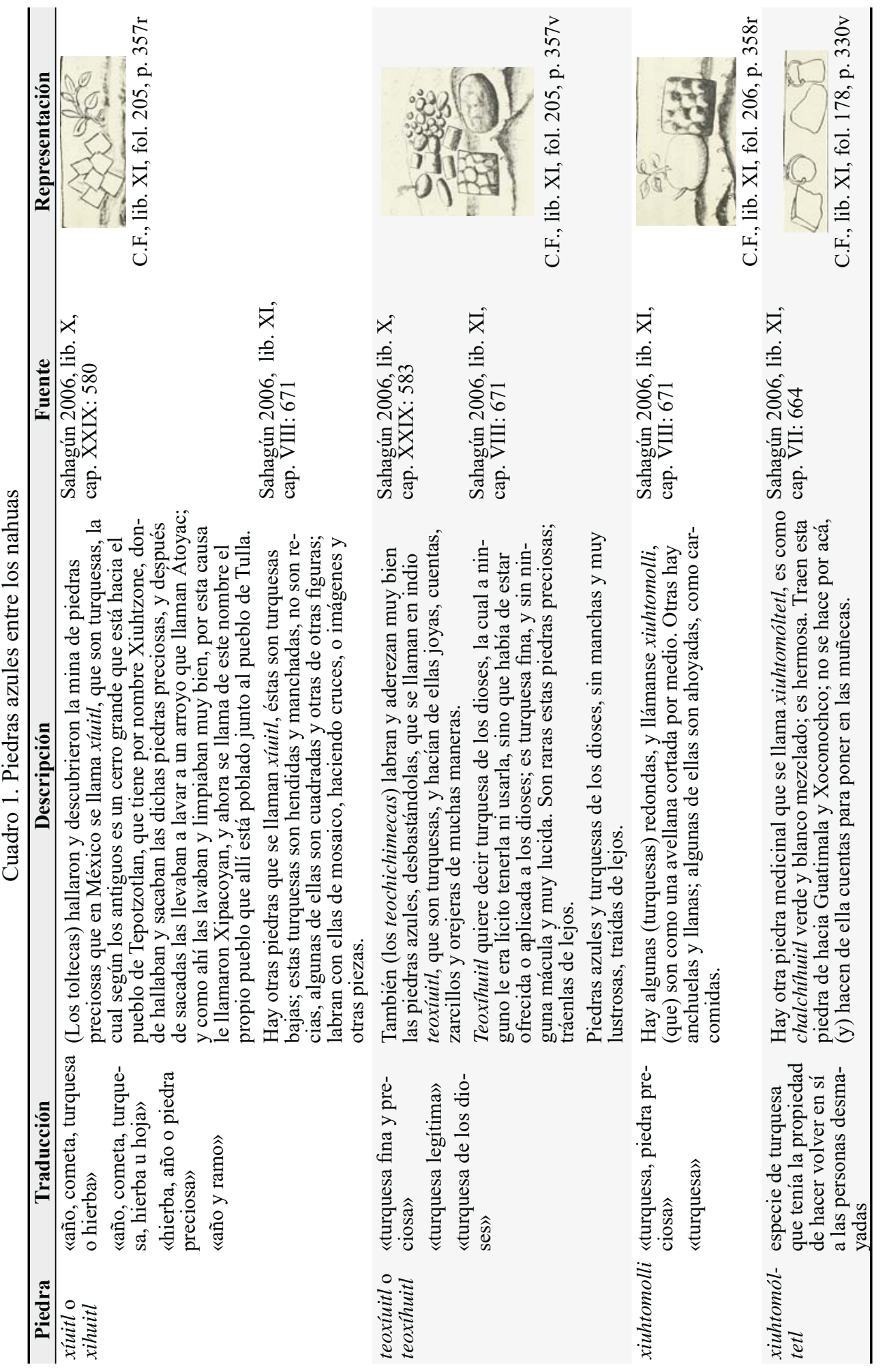


montañas (Gallaga y Blainey 2016), además de tener la habilidad de labrar la turquesa de más alta calidad para hacer joyas, cuentas y orejeras (Melgar 2014: 274-275).

\section{La clasificación de las turquesas entre los nahuas}

Gracias a las fuentes escritas se conoce la gran cantidad de nombres en náhuatl que indican la variabilidad de los materiales pétreos empleados por los artesanos lapidarios. En la elaboración de estas clasificaciones y nomenclaturas, el criterio para ordenarlas parece haber sido el cromático, el cual estaba vinculado con la vida ritual de los grupos mesoamericanos y la conceptualización simbólica atribuida a cada color dentro de su cosmovisión. También se señalaban varias características de cada piedra, como su dureza, brillo, localización de yacimientos, su uso con fines ornamentales y las propiedades medicinales en caso de tenerlas.

En esta clasificación lingüística, el color se evocaba mediante un objeto de referencia que tenía dicho matiz, por lo cual su nomenclatura muchas veces quedaba asociada a un material ideal en que se presentaba. Sin embargo, ello no implicaba que la designación del color indicara necesariamente el material del cual estaba hecho un objeto.

A partir de ello es posible apreciar que las características físicas de los materiales pétreos, en especial la descripción de su color y su empleo, fueron los atributos más importantes. Por ejemplo, Sahagún (2006, lib. XI, cap. VII: 664-666; cap. VIII: 670673 ) agrupa las piedras primero por su uso (ornamental y medicinal) y luego por su gama cromática (variaciones de color y mezclas de éste). Estos atributos también se ilustraron en la mayoría de las pictografías del Códice Florentino, en especial en las que se representaron las piedras en estado natural y como adornos, ya que aparecen acompañadas de glifos (tetl o piedra, gota de sangre, corriente de agua, vapor, humo y fuego), plumas (de quetzal), animales (colibrí), plantas (flores o hierba) u otros objetos (bloque de obsidiana y cuenta de piedra) que aluden a su apariencia, brillo, tonalidad y simbolismo.

En el caso de las turquesas, entre sus acepciones están hierba y hoja, pero también aluden al fuego, al linaje, a la realeza, al cometa y al año (Molina 1944: 159v; Siméon 2010: 770); su relación con las hierbas y hojas se debe al color verde-azul que presentan algunas de ellas, mientras que el brote de nuevas hojas se asocia con el ciclo anual del movimiento solar; así, un manojo de hierba simboliza el inicio de un nuevo año y el atado de un ramo o de palos es la representación de 52 años transcurridos o un ciclo de Fuego Nuevo en el mundo mesoamericano. Según Sahagún, el significado de turquesa viene del color verde-azul de la hierba fresca que crece alrededor de las piedras verdes preciosas porque son su aliento. En cuanto a su relación con el fuego y el calor, el azul representa el centro de la llama y los ornamentos azules y de turquesa los portan las deidades del fuego como Xiuhtecuhtli. Su asociación con cometas u otro fuego celeste se vincula con la Xiuhcóatl o serpiente de fuego de la cual emergen. También se empleaba como metáfora de lo precioso, la energía, la pureza de la vida, el linaje y el poder de los gobernantes (Izeki 2008).

Existen distintas piedras de turquesa que contienen xihuitl en su nombre, como teoxihuitl, empleada para describir la turquesa fina, de los dioses, la más valorada; xiuhmatlaliztli para las piedras preciosas de color azul similar a zafiro; xiuhtomolli para las turquesas redondas 
También existen imágenes del Códice Florentino (Sahagún 1979, lib. XI, fol. 205: 357r-358v) en el que se incluyen complementos fonéticos, como hierbas en todas las piedras con el vocablo xihuitl. En otros documentos, como la Matrícula de Tributos y el Códice Mendocino, los colores indican o refuerzan el material lapidario que están representando, como el azul para los objetos de turquesa (xihuitl) que contrasta con el verde empleado para las cuentas de piedra verde (chalchihuitl).

Sahagún y sus informantes también nos proporcionan datos de la localización de los yacimientos de algunas piedras azules. En ocasiones tales datos son muy específicos, como en el caso de una de las minas donde se obtenían turquesas xihuitl, ya que los antiguos decían que estaba en el cerro Xiuhtzone cerca de Tepotzotlán, aunque los estudios geológicos modernos no han podido comprobar su existencia en los alrededores de ese pueblo. Otras veces son muy vagos, como en el caso de la piedra teoxihuitl, la cual señala que es traída de lejos sin aclarar la dirección (Sahagún 2006, lib. XI, cap. VIII: 671), aunque podemos inferir que viene del norte debido a que en otro apartado del mismo documento indica que la trabajaban los teochichimecas, grupos de cazadores que habitaban en los montes y cuevas septentrionales (Sahagún 2006, lib. X, cap. XXIX: 583).

Cabe señalar que la información sobre los materiales pétreos debe tomarse con cuidado al tratar de identificarlos con rocas y minerales modernos, ya que, en la obra de Sahagún, por ejemplo, aparecen varias menciones de las «mismas» piedras en náhuatl con diferentes cualidades y características, a veces contradictorias. Parte del problema radica en que el escrito de Sahagún, como cualquier otro documento, debe revisarse en su totalidad y no solamente en los capítulos de las piedras medicinales y los lapidarios, para comparar las distintas descripciones de los mismos materiales pétreos, tratando de revelar si pudieran estar hablando de diferentes materias primas. Ello ha complicado su clasificación geológica moderna, pues hay varias rocas y minerales que presentan las características descritas en las fuentes históricas.

Esta problemática en la identificación mineralógica la presenta la piedra llamada tlapalteoxihuitl, la cual aparece descrita como «turquesa fina colorada» y considerada como el rubí de la Nueva España (Sahagún 2006, lib. XI, cap. VIII: 671). Su color rojo parece venir de tlapalli, pero éste contrasta con la segunda parte de su nomenclatura (teoxihuitl), ya que ninguna turquesa es de tonalidad roja sino azulverdosa. Desafortunadamente, su dibujo no ayuda a resolver lo anterior, pues carece de color (Sahagún 1979, lib. XI, fol. 206: 358v), por lo cual la imagen de la cuenta de piedra asociada a una planta solamente está haciendo referencia a parte de su nombre, xihuitl.

\section{La variedad de objetos de turquesa ofrendados y su simbolismo}

Durante las excavaciones arqueológicas realizadas en el Templo Mayor de Tenochtitlan, desde 1978 hasta 2006, se han recuperado objetos de turquesa en 16 ofrendas depositadas en el Huey Teocalli y en dos de las oblaciones de las edificaciones aledañas. Al comparar su distribución espacial y temporal en las ofrendas, encontramos que la gran mayoría de piezas se concentra en el Huey Teocalli, sobre todo en la etapa IVb, siendo escasas en los edificios aledaños (Figura 6), y destaca el mosaico irregular con cuatro círculos en el borde de la Ofrenda K. 


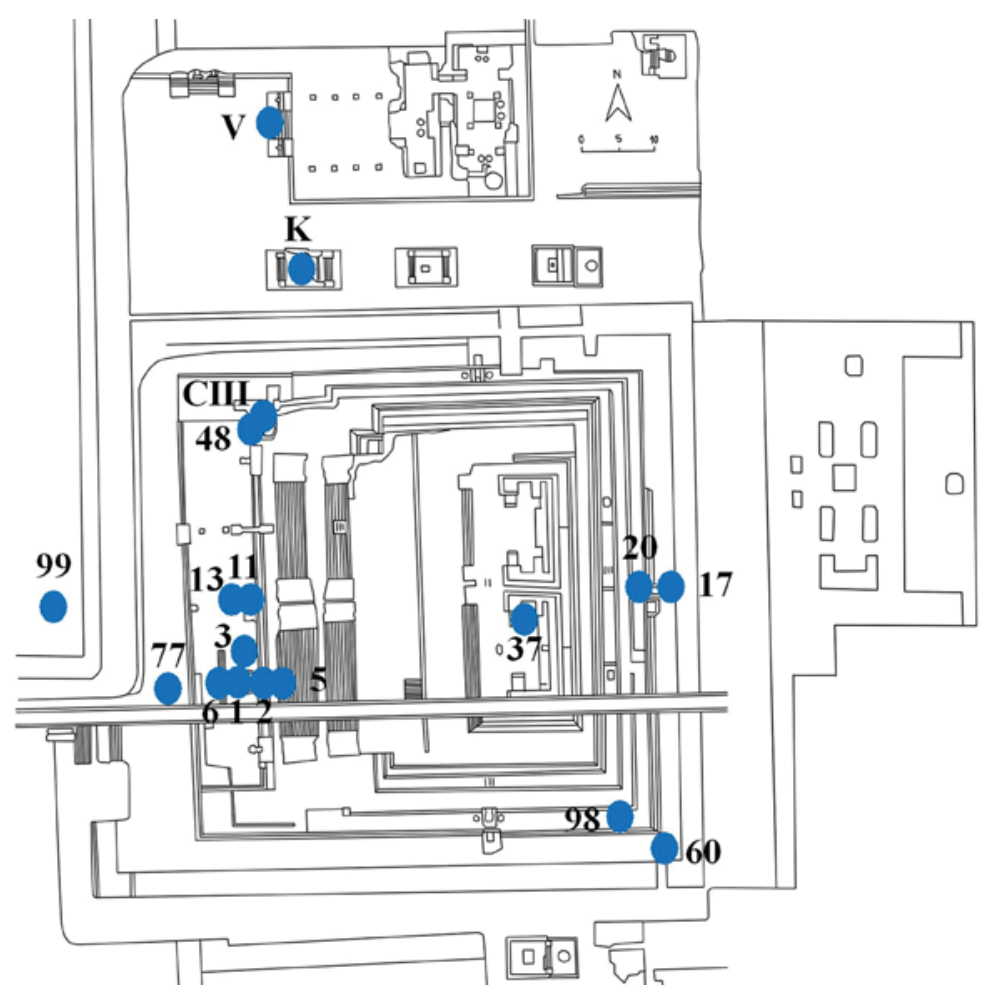

Figura 6. Plano del Templo Mayor con la ubicación de ofrendas en las que se recuperaron objetos de turquesa. (Plano elaborado por Emiliano Melgar y Víctor Solís).
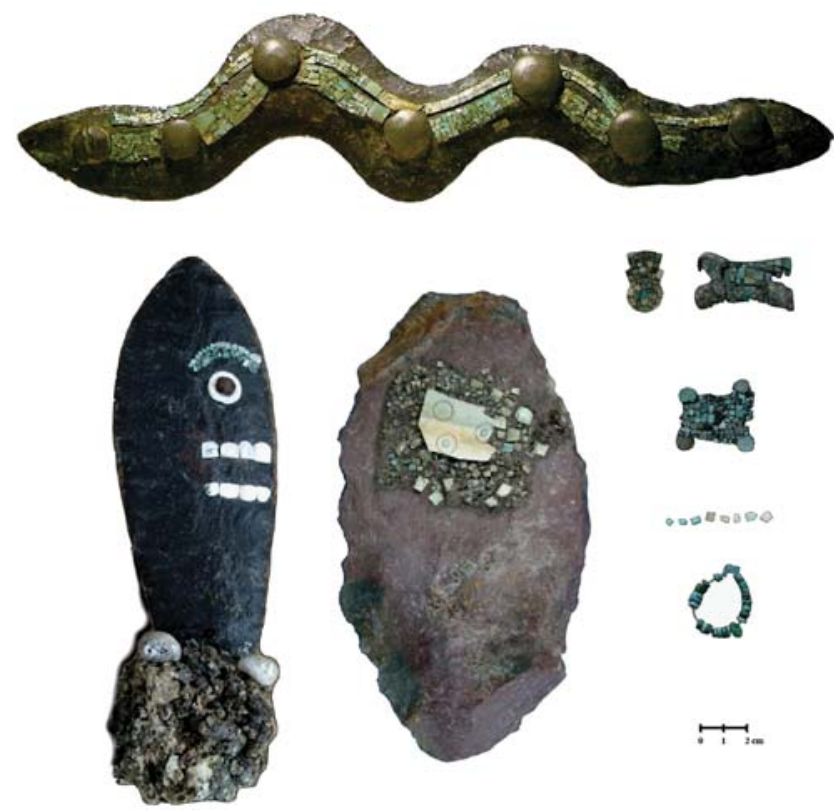

Figura 7. Ejemplos de objetos de turquesa recuperados en las ofrendas del Templo Mayor de Tenochtitlan. (Fotografía de Emiliano Melgar). 
Cuadro 2. Tipología resumida de los objetos de turquesa del Templo Mayor de Tenochtitlan

\begin{tabular}{|c|c|c|c|c|}
\hline \multirow[t]{2}{*}{ Objeto } & \multicolumn{2}{|c|}{ Cantidad } & \multirow[t]{2}{*}{ Ofrenda $n^{0}$} & \multirow{2}{*}{$\begin{array}{c}\text { Etapa } \\
\text { Constructiva }\end{array}$} \\
\hline & C & $\mathbf{F}$ & & \\
\hline \multirow[t]{3}{*}{ Incrustaciones sueltas } & 10824 & 108 & $\begin{array}{l}1(1879), 3(1293), 11(1188), \\
13(1780), 17(1445), 20(1669), \\
60(768) \text { y } 98(902)\end{array}$ & $\mathrm{IVb}$ \\
\hline & 5 & & 77 & V \\
\hline & 2 & & V & VI \\
\hline \multirow[t]{3}{*}{ Cuentas } & 26 & - & 37 & II \\
\hline & 8 & - & 1 y $2(7)$ & $\mathrm{IVb}$ \\
\hline & 1 & - & 77 & V \\
\hline Pendientes & 3 & - & 1 y $98(2)$ & $\mathrm{IVb}$ \\
\hline $\begin{array}{l}\text { Nariguera circular con trapecios } \\
\text { escalonados }\end{array}$ & 2 & - & 11 & $\mathrm{IVb}$ \\
\hline $\begin{array}{l}\text { Pectoral en forma de "X" con } \\
\text { lados escalonados }\end{array}$ & 2 & - & 17 & $\mathrm{IVb}$ \\
\hline Tapas circulares de orejera & 4 & - & $6(2)$ y $17(2)$ & $\mathrm{IVb}$ \\
\hline $\begin{array}{l}\text { Cuchillo rostro con ceja de tur- } \\
\text { quesa }\end{array}$ & 5 & - & $6(2), 11,13$ y 98 & $\mathrm{IVb}$ \\
\hline $\begin{array}{l}\text { Cetro serpentiforme decorado } \\
\text { con turquesas }\end{array}$ & 1 & - & Cámara III & IVa \\
\hline $\begin{array}{l}\text { Mosaico circular con cuatro } \\
\text { círculos en el borde }\end{array}$ & 3 & - & Contreras-Angulo & $\mathrm{IVb}$ \\
\hline $\begin{array}{l}\text { Mosaico irregular con cuatro } \\
\text { círculos en el borde }\end{array}$ & 1 & - & $\mathrm{K}$ & VI \\
\hline $\begin{array}{l}\text { Preforma de pedernal decorado } \\
\text { con turquesa }\end{array}$ & 1 & - & 17 & $\mathrm{IVb}$ \\
\hline $\begin{array}{l}\text { Disco de mosaico con teselas } \\
\text { geométricas }\end{array}$ & $\begin{array}{l}1 \\
1\end{array}$ & - & $\begin{array}{l}48 \\
11\end{array}$ & $\begin{array}{l}\text { IVa } \\
\text { IVb }\end{array}$ \\
\hline $\begin{array}{l}\text { Disco de mosaico con teselas } \\
\text { incisas }\end{array}$ & 1 & - & 99 & VII \\
\hline No determinable & 1 & 2 & 13 (2) y MSD & $\mathrm{IVb}$ \\
\hline Piezas reutilizadas & 5 & - & $1,11,17(2)$ y 20 & $\mathrm{IVb}$ \\
\hline Total & $\begin{array}{r}10897 \\
11\end{array}$ & $7^{110}$ & & \\
\hline
\end{tabular}

C: completos; F: fragmentos. En caso de haber dos o más piezas en una misma ofrenda se señala el número de ellas entre paréntesis.

Para conocer la diversidad de piezas elaboradas fue necesario clasificarlas tipológicamente según su forma y función (Melgar 2014), determinándose un total de quince categorías, como puede verse en el Cuadro 2, de las cuales casi la totalidad son mosaicos o incrustaciones sueltas o desarmadas de los mismos, mientras que las cuentas y pendientes son minoría en la colección (Figura 7).

Con respecto a su morfología y simbolismo, varios de los mosaicos de turquesa presentan siluetas de adornos e insignias de divinidades que aparecen de color azul en las representaciones pictóricas de códices, o se señala que son de este material en los documentos escritos. También su comparación con esculturas y piezas arqueológicas de otros sitios permitió identificar algunos de sus usos y significados. De esta manera, se destacan los siguientes objetos de la colección del Templo Mayor de Tenochtitlan:

- Las dos narigueras circulares con trapecios escalonados de la Ofrenda 11 están hechas de la concha nacarada Pinctada mazatlanica sobre las que adhirieron teselas de turquesa (Figura 8a). Esta silueta coincide con la nariguera de tur- 


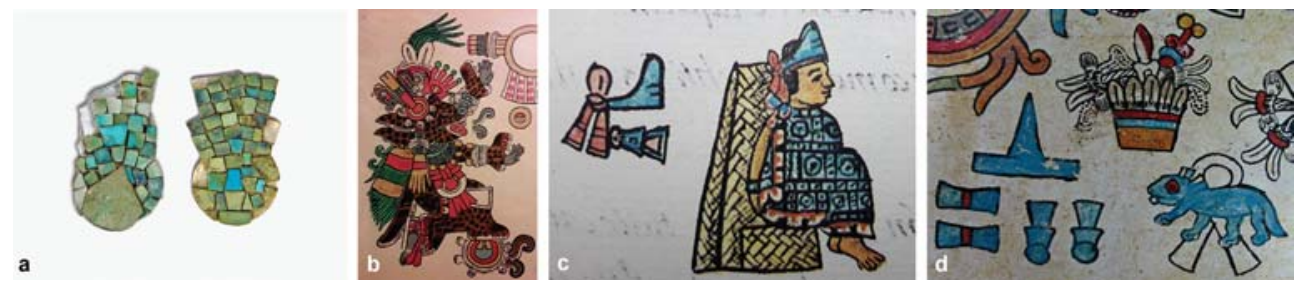

Figura 8. Comparación de las narigueras yacaxihuitl halladas en el Templo Mayor (a), con las que portan Tezcatlipoca en su advocación de Tepeyólotl en el Códice Borbónico (b), Moctezuma II en el Códice Florentino (c) y como ofrenda mortuoria en el Códice Borbónico (d). (Fotografía de Emiliano Melgar).
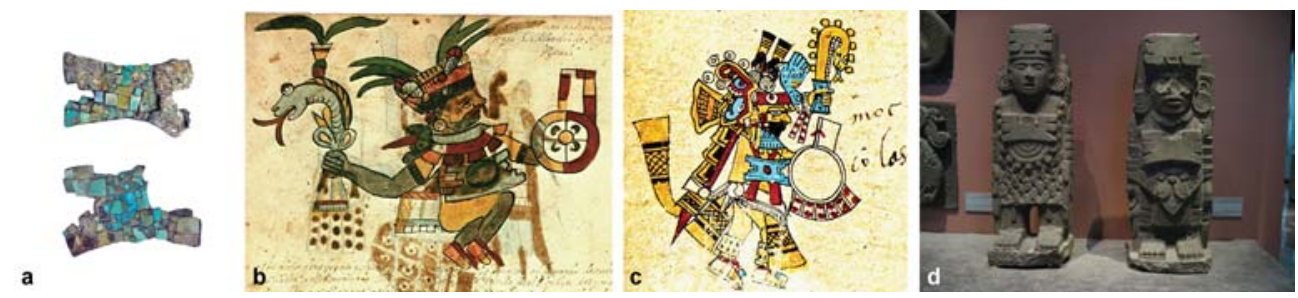

Figura 9. Comparación de los pectorales de mariposas estilizadas halladas en la ofrenda del Templo Mayor (a), con el que portan Xiuhtecuhtli en el Códice Ixtlilxóchitl (b), Moctezuma II ataviado como Xiuhtecuhtli en el Códice Borbónico (c) y las esculturas de atlantes recuperadas cerca de la cancha del juego de pelota de Tenochtitlan (d).

(Fotografías de Jonathan Silva y Emiliano Melgar).

quesa llamada yacaxihuitl, relacionada con deidades del fuego y la alianza de señoríos. Este adorno lo portan varias divinidades de carácter ígneo (Noguez 1975: 85-86; Velázquez 1999: 95-98), como en una escultura de Xiuhtecuhtli, el dios del fuego, que se encuentra en la Sala Mexica; o en los códices con Chantico, la diosa del fuego del hogar; y Tezcatlipoca en su advocación como Tepeyólotl (Figura 8b). También Moctezuma II tiene una nariguera azul de forma similar a la yacaxihuitl como parte de su antropónimo o glifo onomástico (Figura 8c), probablemente relacionado con Xiuhtecuhtli como protector de la realeza y su simbolismo con la toma de poder y el nombramiento de tecuhtli o gobernante. Esta asociación de los ornamentos de turquesa, como diademas, narigueras y orejeras, con el fuego y los bultos mortuorios, se aprecia también en las ceremonias en las cuales se rememora a los guerreros y a los nobles muertos, como aparece en las trecenas «Uno Serpiente» y «Uno Pedernal» ilustradas en el Códice Borbónico (Figura 8d).

- Los dos mosaicos en forma de «X» con lados escalonados (Figura 9a) son similares a los pectorales de mariposa de Xiuhtecuhtli en el Códice Borbónico y en el Códice Ixtlilxóchitl (Figura 9b). También es uno de los adornos que tiene Moctezuma II en el Códice Borbónico durante la ceremonia de entronización, cuando aparece ataviado como Xiuhtecuhtli en la fiesta de Izcalli, como muestra de agradecimiento por haber sido elegido gobernante (Figura 9c). Estos pectorales también los portaban los militares del alto rango, combinados con discos lumbares de turquesa, y representaban las almas de los guerreros muertos convertidas en mariposas al ser cremados sus cuerpos (Taube 2012: 


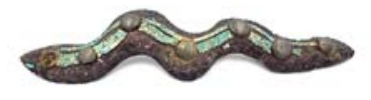

a
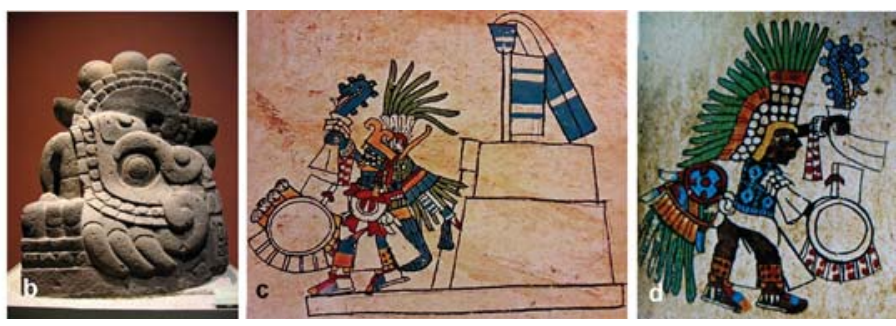

Figura 10. Comparación del cetro Xiuhcóatl hallado en la Cámara III del Templo Mayor (a) con el monolito exhibido en el Museo Nacional de Antropología (b) y el cetro que portan Huitzilopochtli (c) y Xiuhtecuhtli (d) en el Códice Borbónico.

(Fotografías de Jonathan Silva y Emiliano Melgar).

125-126; Castillo y Olmedo 2016: 60). Adornos con esta forma se aprecian en los enormes atlantes de Tula y en las esculturas de menor tamaño inspiradas en ellos hechas por los mexicas, las cuales fueron halladas cerca de la cancha principal del juego de pelota frente al Templo Mayor de Tenochtitlan (Figura 9d).

- El cetro serpentiforme hecho en pedernal y decorado con piezas de turquesa y pirita (Figura 10a) fue recuperado en la Cámara III y representa a la serpiente de turquesa o de fuego llamada Xiuhcóatl. En los códices y esculturas esta serpiente fantástica aparece representada con la mandíbula superior semirredondeada y decorada con círculos que representan estrellas u ojos estelares, el cuerpo está dividido con diseños rectangulares o trapezoidales, con dos patas delanteras, y su cola termina en un rayo que sale de un trapecio similar al glifo del año (Hermann 2009: 68-69; Castillo y Olmedo 2016: 80). Debido a estas características anatómicas, sobre todo las patas y el cuerpo segmentado, Taube (2000: 287; 2012: 130-131) considera que la xiuhcoatl es una oruga sobrenatural antes de transformarse en mariposa y que también representa meteoros o cometas. Ejemplos de esta serpiente u oruga se aprecian en la parte inferior de la Piedra del Sol y en dos cabezas monumentales de este ser fantástico de estilo mexica (Figura 10b), las cuales se relacionan con el Sol, el fuego, los rayos y el calor de este astro, así como con el encendido del Fuego Nuevo con el bastón mamalhuaztli (Hermann 2009: 70; Castillo y Olmedo 2016: 84-89). También aparece en el mito del nacimiento de Huitzilopochtli en el Cerro Coatepec, ya que esta serpiente hecha de teas fue encendida y empleada por este dios como arma sagrada y letal para matar a su hermana Coyolxauhqui y a sus 400 hermanos llamados Centzonhuitznahua (Sahagún 2006, lib.III: 185). Imágenes de esta insignia de color azul, y a veces con achurado simulando las teselas de turquesa, la empuñan Huitzilopochtli (Figura 10c), Xiuhtecuhtli (Figura 10d) y Pahtécatl en el Códice Borbónico.

- Los tres mosaicos circulares y el mosaico irregular con cuatro círculos en el borde representan el glifo xihuitl (Figura 11a). El detalle dentro del círculo central de cambio de tonalidad de azul en el centro y negro hacia los lados se parece al elemento central del tocado que porta en la frente Quetzalcóatl en el Códice Telleriano-Remensis (Figura 11b) y en sus advocaciones como Ehécatl (Figura 11c) y Xólotl (Figura 11d) en el Códice Borbónico. Izeki (2008: 53) 


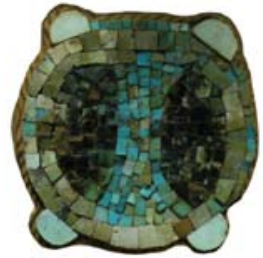

a

Figura 11. Comparación del mosaico en forma del glifo teoxihuitl hallado en el Templo Mayor (a), con los tocados que portan Quetzalcóatl en el Códice Telleriano-Remensis (b), Ehécatl (c) y Xólotl (d) en el Códice Borbónico. (Fotografía de Emiliano Melgar).

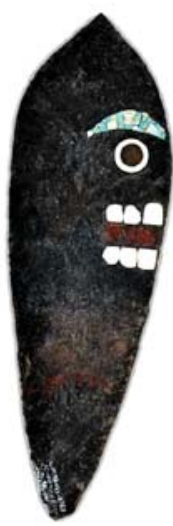

Figura 12. Comparación de un cuchillo rostro con ceja de mosaico de turquesa hallada en Templo Mayor (a), con las personificaciones de este cuchillo que presentan Xipe Tótec (b) e Iztapaltotec (c). (Fotografía de Jonathan Silva).

considera que este dios portando este tocado aparece como el creador de la humanidad presente y que preside el tiempo en las fiestas de Etzalcualiztli, Panquetzaliztli y Tititl. La silueta de este ornamento también se parece al glifo que forma parte de los topónimos de Chalco y Xiuhtepec en el Códice Mendocino, aludiendo al concepto de turquesa vinculado con lo precioso.

- Los cinco cuchillos rostro hechos de pedernal con cejas de turquesa (Figura 12a) podrían ser representaciones o personificaciones de Xipe Tótec (Figura 12b) o Iztapaltotec (Figura 12c), ya que estas deidades aparecen ataviadas de esta manera según Izeki (2008), y estos instrumentos eran reverenciados cuando se empleaban en los sacrificios humanos (Torquemada 1975, lib. VI, cap. XXVI: 89).

- Hay dos discos de mosaico, uno solamente con teselas geométricas y el otro con varias incrustaciones incisas que conforman siete personajes:

El primero de ellos (Figura 13a) estuvo montado sobre una base de madera y combinado con placas de caparazón de tortuga. En sitios de Puebla y 


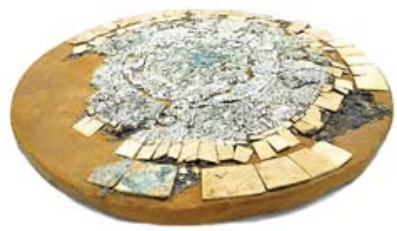

a

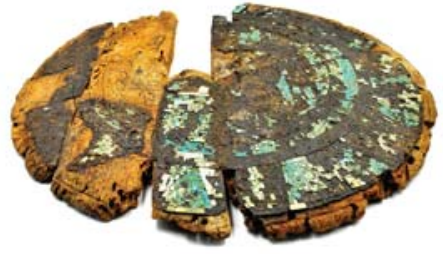

b

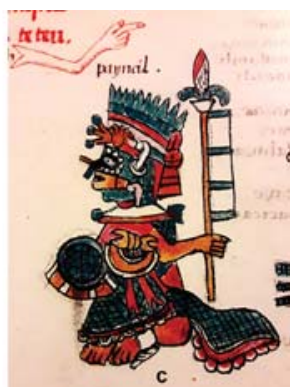

Figura 13. Comparación del disco de turquesa hallado en la Ofrenda 48 del Templo Mayor (a) con disco de Santa Ana Teloxtoc (c) y con el escudo que porta Paynal en los Primeros Memoriales (b). (Fotografías de Jonathan Silva).
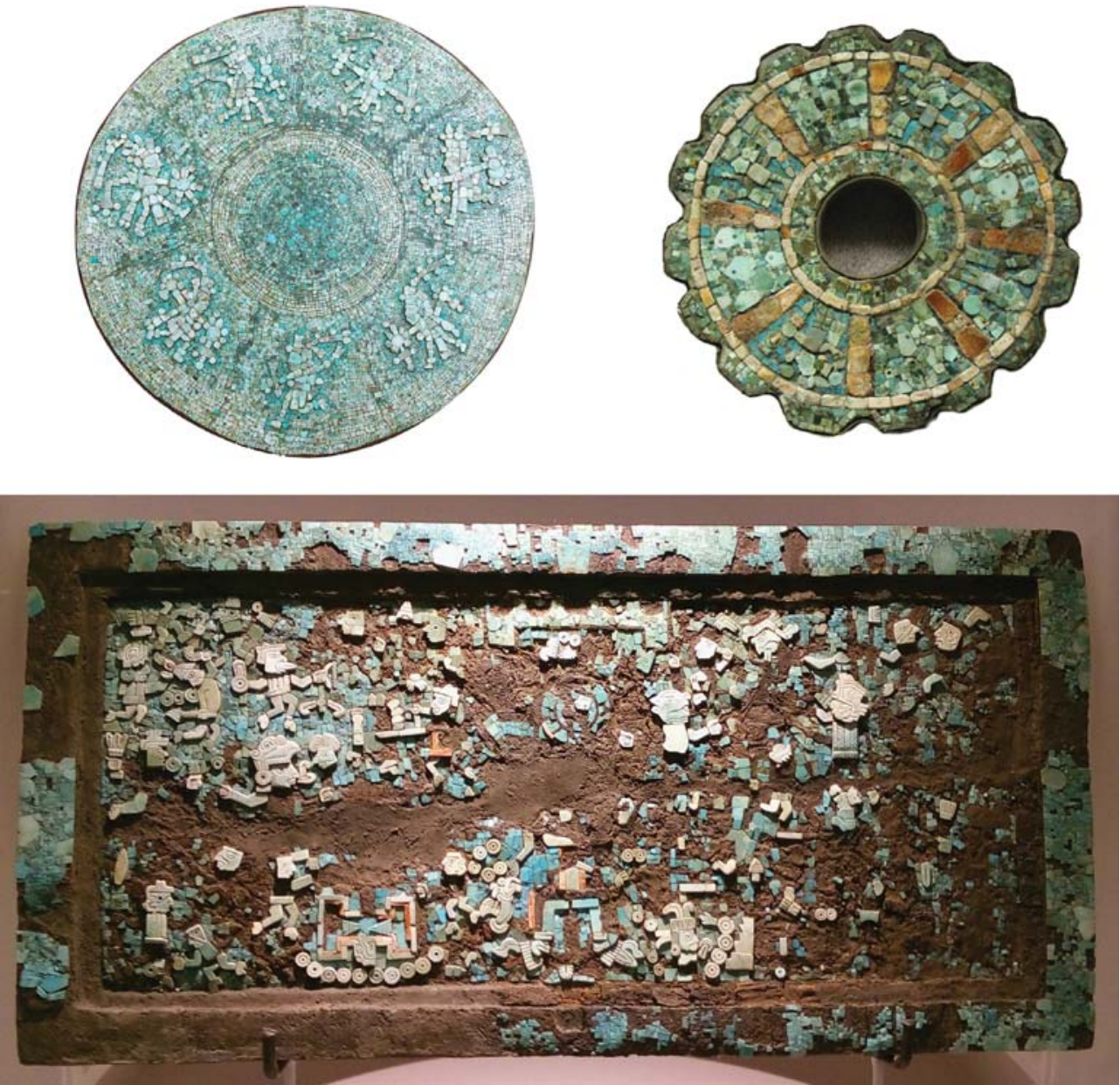

Figura 14. Comparación del disco de turquesa de la Ofrenda 99 del Templo Mayor (a), con el disco de Zaachila (b) y la tableta de la Cueva Chevé (c).

(Fotografías de Emiliano Melgar). 
Oaxaca se han recuperado piezas similares donde se combinan turquesas con fragmentos de concha u otros minerales o metales (Figura 13b-c). La mayoría son parte de los ajuares de bultos sagrados guardados en cuevas donde se les rendía culto como materializaciones de los ñuhus, seres subterráneos que fueron vencidos por los mixtecos en una guerra primordial en los tiempos míticos (Domenici 2016: 44-48), pero también por su forma podrían ser escudos de turquesa llamados xiuhchimalli (Olko 2005: 301), como los que porta el dios Paynal en el Códice Florentino (Sahagún 1979) y en los Primeros Memoriales (Sahagún 1993) (Figura 13d).

El otro disco de mosaico (Figura 14a) tiene las representaciones de siete guerreros ataviados como dioses, entre ellos están Huitzilopochtli, Tlahuizcalpantecuhtli, Mixcóatl y el Dios del Maíz (Velázquez et al. 2012: 79-81). La presencia de estos personajes simboliza el viaje cíclico de las estrellas por el inframundo, cuyo ritual de inhumación pudo ser hecho en la veintena Quecholli cuando se conmemoraba el mito de la creación del mundo y el descenso de las estrellas a la Tierra (Velázquez et al. 2012: 84). En las tumbas de Zaachila (Figura 14b) y en cuevas de Oaxaca y Puebla se han recuperado mosaicos con escenas de personajes, pero también en tabletas rectangulares, como una de la Cueva Chevé (Figura 14c) en la que se representa la guerra primordial entre los mixtecos que vencieron a los ñuhus para legitimar la posesión de la tierra por parte de los primeros (Domenici 2016: 45-46). Aunque podrían ser escudos como los discos sin decoración incisa, las escenas representadas les conferían un valor similar a los códices al servir de referentes visuales de acciones o momentos muy importantes que buscaban destacarse y rememorarse continuamente.

Llama la atención que ninguno de los discos de mosaico de turquesa recuperados en el Templo Mayor tiene en el centro una pieza circular de pirita, para ser considerados espejos lumbares o tezcacuitlapilli, como ocurre con los hallados en Tula y Chichén Itzá que representaban al Sol rodeado de la Xiuhcóatl. Tampoco se parecen a los que portan en la espalda las esculturas de guerreros inspirados en los atlantes ni al glifo del tianquiztli del monolito de Chalco, el cual presenta parte del diseño de estos espejos lumbares, pero el borde almenado de los discos toltecas lo ocupan conjuntos de cuatro barras y un círculo decorado con pequeños discos (Castillo y Olmedo 2016: 60-61; Gallaga y Blainey 2016).

- Finalmente, podemos destacar los restos de mosaicos desarticulados de la Ofrenda 3, compuesto por teselas geométricas y con decoraciones incisas (Figura 15). Algunos de los diseños representan el pie serpentino o el espejo humeante de Tezcatlipoca, pero también plumones que portaban los sacrificados. Aunque es imposible recuperar la forma original de estas piezas, llama la atención que todas las turquesas están quemadas, y adquirieron un color negro y grisáceo debido a su exposición al fuego. Esta característica particular podría deberse a que el ritual de terminación de esta oblación fue quemar los dones preciosos de manera intencional, como si al matarlos simbólicamente mediante el fuego se transformaran estos materiales ígneos en esencias sagradas para las divinidades en el más allá. Algo similar se plantea que ocurre en Tula y Chichén Itzá con algunos mosaicos de turquesa circulares con espejos de pirita al centro, ya que aparecen quemados y han perdido su capacidad de reflejar, quizás debido a que 


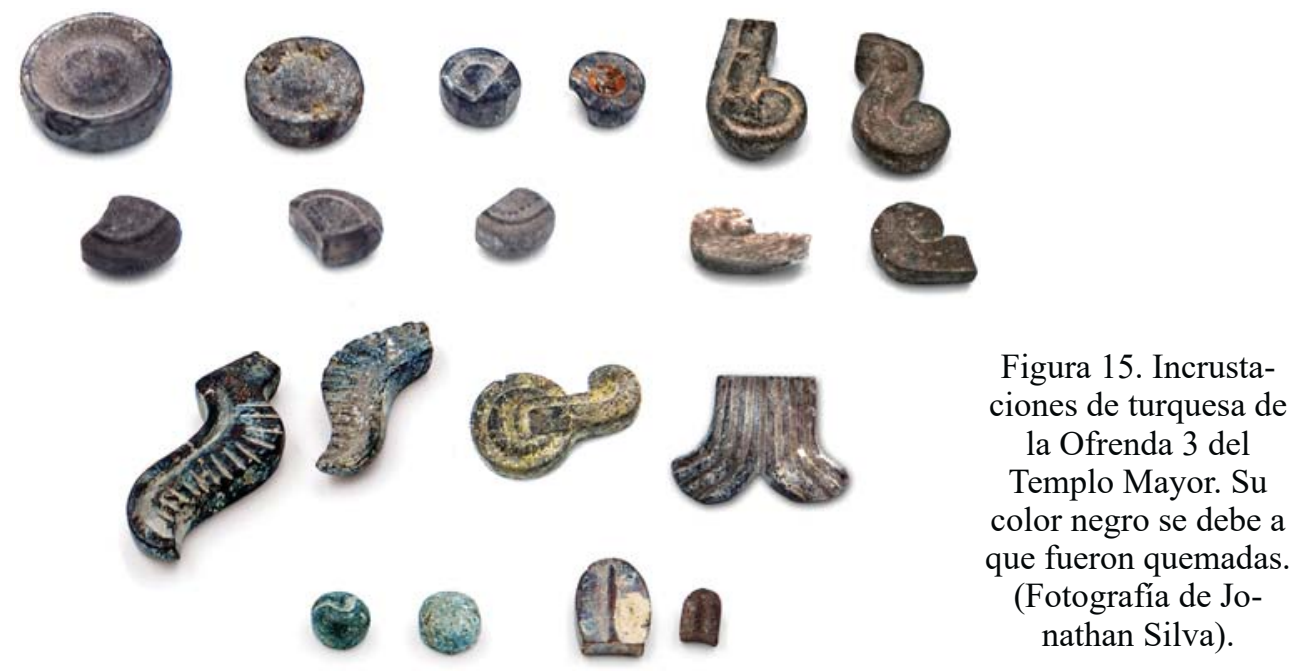

se encendió fuego sobre ellos aludiendo a la ceremonia del Fuego Nuevo o a la entronización de algún dignatario (Castillo y Olmedo 2016: 99-102).

Como es posible apreciar, la mayoría de los mosaicos de turquesa hallados en el Templo Mayor representa ornamentos, divisas y emblemas que portan las divinidades del Centro de México y los gobernantes nahuas; o forman parte de la decoración de objetos ofrendados como bienes sagrados o de prestigio. Algunos de ellos son exclusivos del Templo Mayor de Tenochtitlan, como las narigueras yacaxíhuitl, mientras otros también se han recuperado en varios asentamientos, sobre todo de filiación mixteca, como los discos de mosaico y las cuentas; aunque hay otros más inspirados en culturas anteriores, como los pectorales en forma de mariposa de Tula. Estos dones preciosos contrastan con las piezas de turquesa de culturas enemigas de los mexicas que están ausentes en la colección tenochca, como los tarascos, en cuya capital, Tzintzuntzan, se han recuperado orejeras de obsidiana gris en forma de carrete con teselas de turquesa en su interior y bezotes de obsidiana y oro decorados con turquesa. Estos elementos aparecen representados como marcadores sociales o elementos distintivos de gobernantes, guerreros, sacerdotes y ancestros; destacan los bezotes de turquesa que aparecen recurrentemente en distintas escenas de la Relación de Michoacán como puntos de color azul a la altura de la barbilla de los personajes principales.

\section{La elaboración de los objetos de turquesa}

El estudio de la tecnología de los objetos de turquesa enterrados en el Templo Mayor se hizo a través de la arqueología experimental y la caracterización de huellas de manufactura, dentro del Proyecto «La lapidaria del Templo Mayor: estilos y tradiciones tecnológicas». Para ello se emplearon tres niveles de observación: macroscópico, microscopía estereoscópica de bajas amplificaciones a 10x y 30x, y microscopía electrónica de barrido (MEB) a 100x, 300x, 600x y 1000x. Además, gracias a las comparaciones tecnológicas con colecciones de turquesa y otros minerales azules de distintos sitios 
y temporalidades de Mesoamérica, el Norte de México y el Suroeste de los Estados Unidos, dentro del proyecto «Estilo y tecnología de los objetos lapidarios en el México Antiguo», fue posible identificar tres patrones de manufactura en las piezas de turquesa del Templo Mayor, dos de ellas foráneas y una local (Melgar 2014).

Las cuentas de la Ofrenda 37 y las teselas del cetro de Xiuhcóatl de la Cámara III son las piezas más antiguas y presentan desgastes con arenisca, cortes con obsidiana, perforaciones con pedernal (cuando las tienen) y bruñido con piel (Figura 16). Este
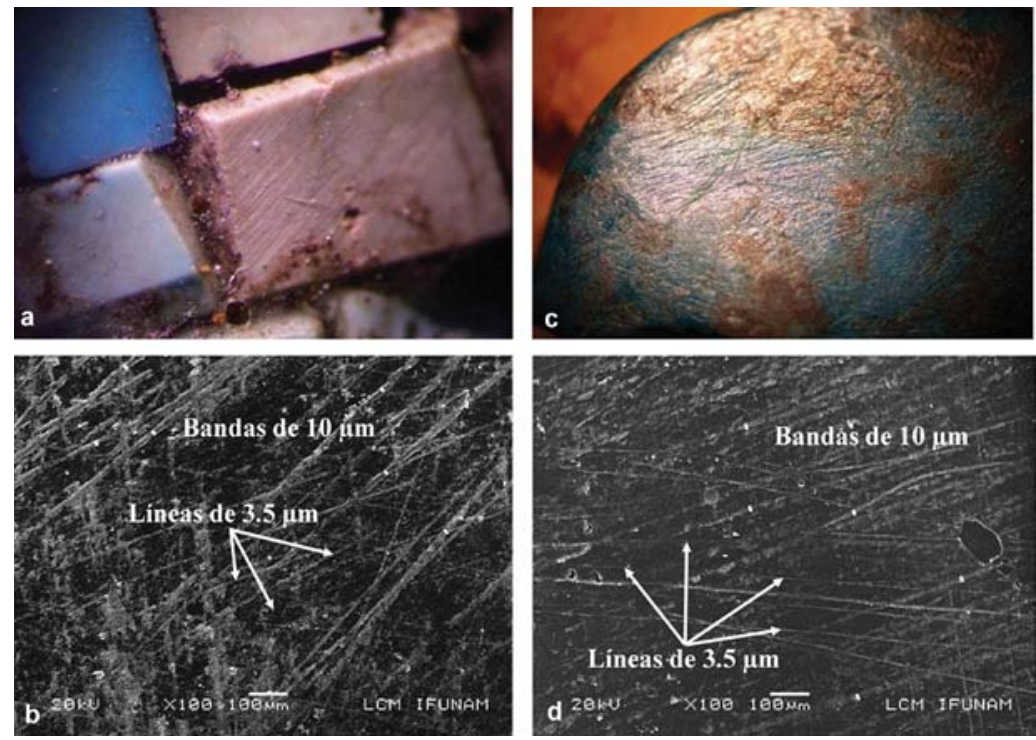

Figura 16. Análisis de superficies de incrustación arqueológica de la Cámara III a 10x (a) y 100x (b) comparada con el desgaste experimental con arenisca y bruñido con piel a 10x (c) y 100x (d). (Fotografías de Emiliano Melgar).
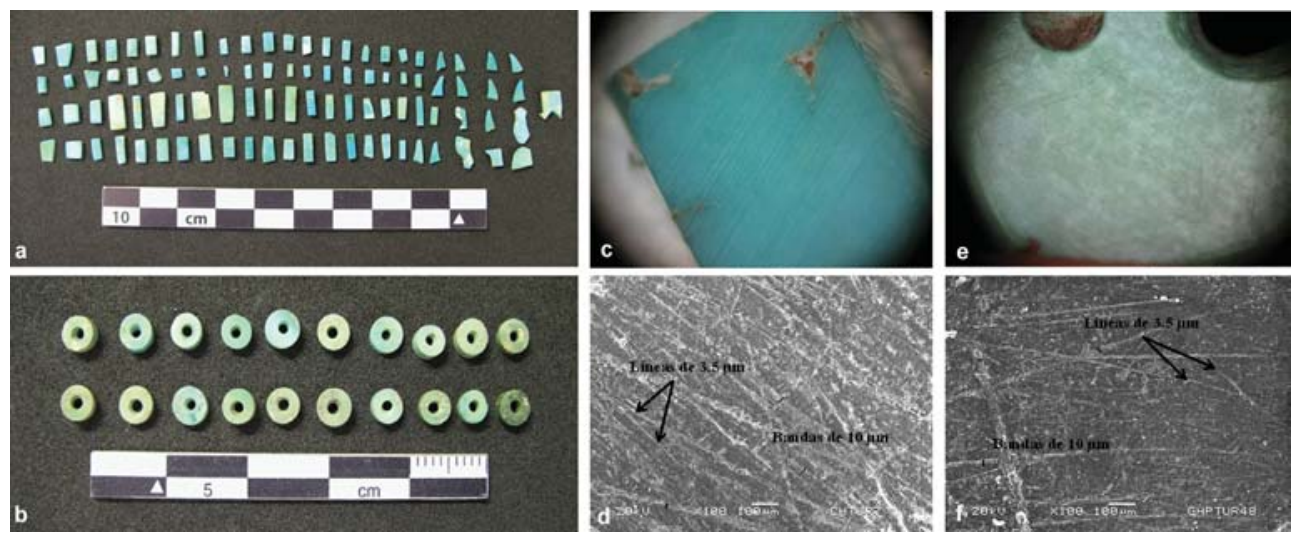

Figura 17. Objetos de turquesa del Suroeste de los Estados Unidos: incrustaciones (a) y cuentas (b) de Chaco Canyon, y las huellas de manufactura de sus superficies a 30x (c) y 100x (d), así como de piezas de Grasshopper Pueblo a 30x (e) y 100x (f). (Fotografías de Emiliano Melgar). 
patrón es similar a los objetos elaborados en los talleres de turquesa en el Noroeste de México (Gallaga y Melgar 2016) y en el Suroeste de Estados Unidos, por lo cual podemos plantear que estas piezas de turquesa fueron manufacturadas parcial o totalmente en tierras septentrionales (Figura 17).

El disco de la Ofrenda 48 presenta desgaste con basalto, corte con obsidiana, pulido con pedernal y bruñido con piel (Figura 18). Estas huellas coinciden con piezas
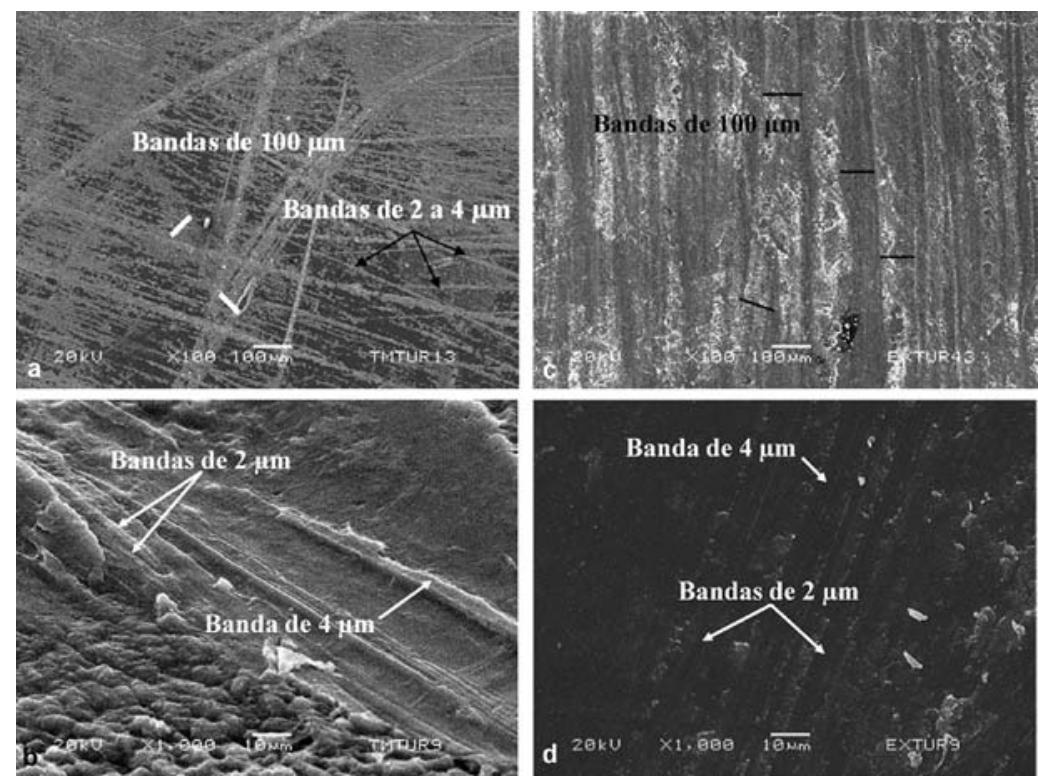

Figura 18. Análisis de superficies de incrustación del disco de la Ofrenda 48 a 100x (a) y 1000x (b) comparada con el desgaste experimental con basalto, pulido con pedernal y bruñido con piel a 100x (c) y 1000x (d). (Fotografías de Emiliano Melgar).
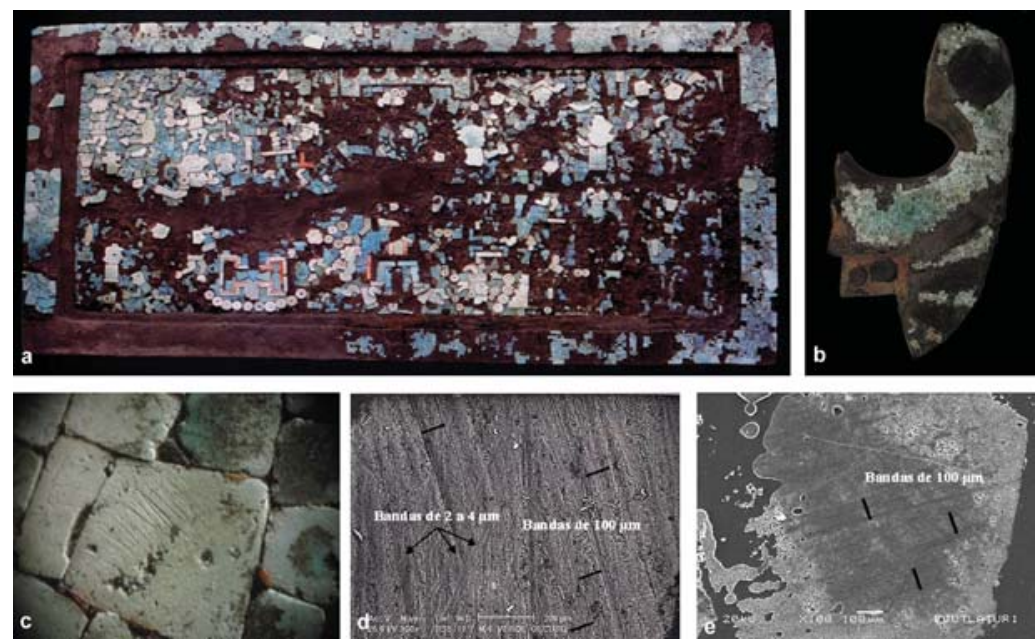

Figura 19. Objetos de turquesa de la Cueva Chevé (a) y la Cueva de Ejutla (b), y las huellas de manufactura de sus superficies a 10x (c) y a 100x (d-e).

(Fotografías de Emiliano Melgar). 
de la Mixteca (Figura 19), por lo cual pudiera tratarse de una pieza saqueada durante las incursiones militares mexicas en esa zona durante el gobierno de Moctezuma I (1440-1469 d.C.), ya que parte de los botines de guerra y despojos eran ofrecidos en festividades al Templo Mayor.

Todos los demás objetos de las etapas IVb a VII (1469-1520 d.C.) presentan una gran estandarización en los desgastes con basalto, cortes e incisiones con obsidiana, perforaciones con pedernal, pulidos con un material de grano fino y bruñidos con piel (Figura 20). Estas piezas comparten la tecnología con otros objetos lapidarios
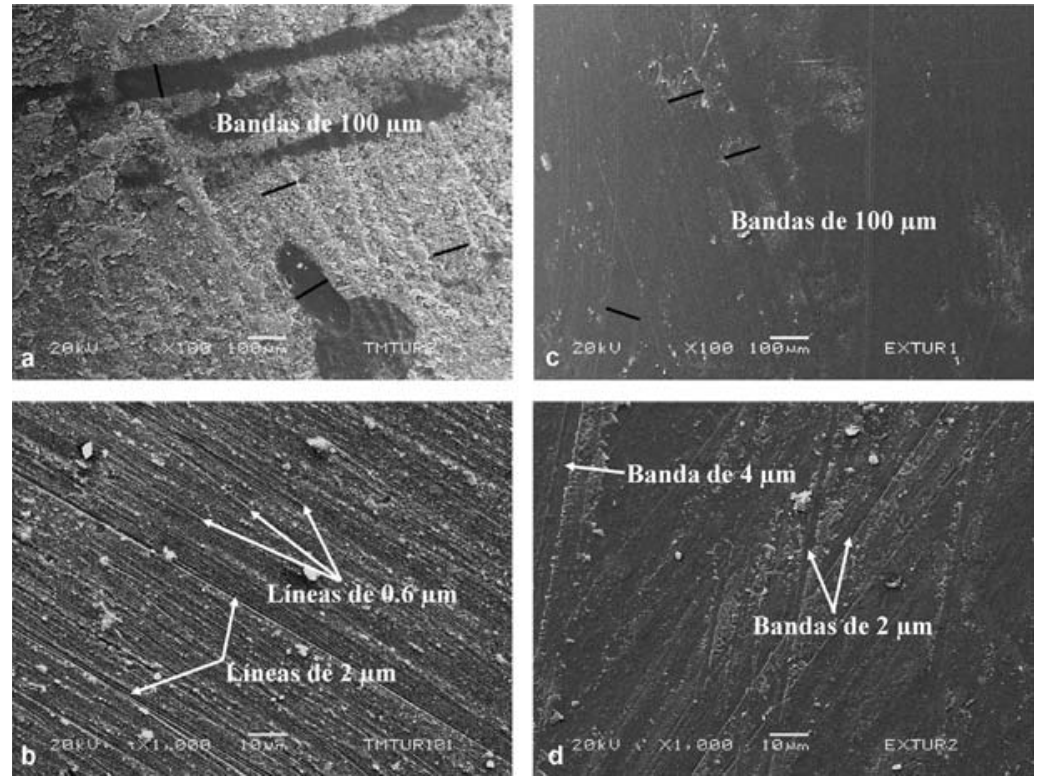

Figura 20. Análisis de superficies de incrustación del disco de la Ofrenda 99 a 100x (a) y 1000x (b) comparada con el desgaste experimental con basalto y pulido con pedernal a $100 \mathrm{x}$ (c) y $1000 \mathrm{x}$ (d). Nótese que el pulidor no identificado de la pieza tenochca es más fino que el pedernal. (Fotografías de Emiliano Melgar).

Figura 21. Objetos de estilo imperial tenochca y el análisis de huellas de manufactura de sus superficies: piezas de obsidiana (a) a 100x (b) y 1000x

(c), comparadas con piezas de travertino (d) a 100x (e) y 1000x (f). (Fotografías de Michel Zabé [a] y Emiliano Melgar [b-f]).
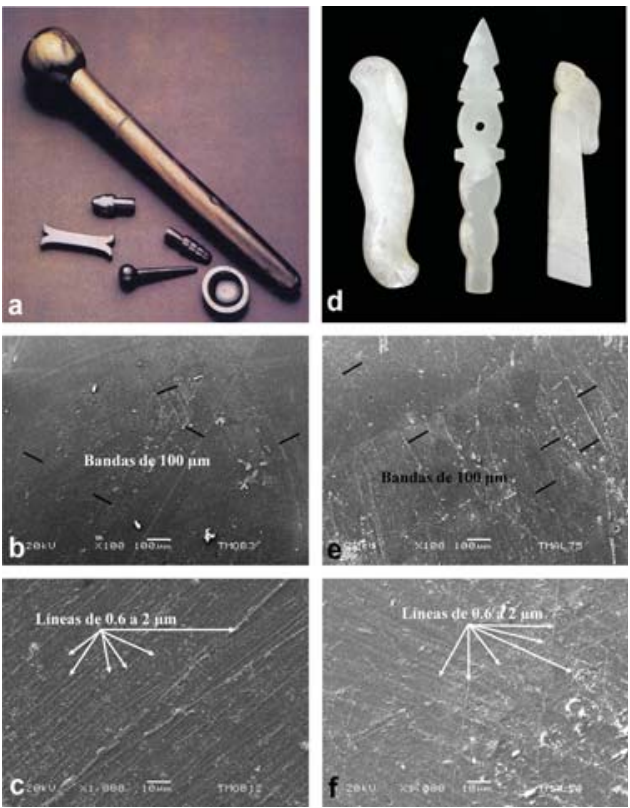
en distintos materiales (obsidiana, travertino, serpentina y jadeíta) que representan insignias de divinidades nahuas o las deidades mismas (Figura 21), las cuales se encuentran casi exclusivamente en las ofrendas del Templo Mayor del periodo imperial, no encontrándose ejemplares idénticos en ningún otro emplazamiento de la Cuenca de México. Ello permite suponer que su producción de estilo imperial tenochca fue local y centralizada, la cual debió estar controlada y supervisada estrechamente por el aparato estatal para el culto religioso más cerrado y elitista, como era la inhumación de ofrendas en su templo principal.

\section{El tributo de turquesas y el Templo Mayor}

De acuerdo con la Matrícula de Tributos y el Códice Mendocino, tres provincias (Quiyauhteopan, Yohualtepec y Tochpan) tributaban materiales pétreos azules a Tenochtitlan (Figura 22): una cazuela con turquesas, un paquete con diez máscaras, dos collares y dos discos de mosaicos. Debido a que estos señoríos se ubicaban geográficamente en la Mixteca Baja, la Montaña de Guerrero y la Huasteca Veracruzana, se ha planteado que estas piezas pudieran ser manufacturas mixtecas o huastecas. Sin embargo, haciendo un recuento de los objetos de turquesa hallados en esas regiones, encontramos que son sumamente escasos en Guerrero y Veracruz, pero muy abundantes en Oaxaca y Puebla (Melgar 2014).

Al comparar los materiales tributados con las turquesas recuperadas en las ofrendas del Templo Mayor de Tenochtitlan, llama la atención que prácticamente no se han recuperado objetos similares a los referidos en los documentos históricos, ya que, salvo un par de sartales y dos discos, no hay cazuelas con turquesas ni máscaras de madera decoradas con teselas. Su escasez en las ofrendas puede deberse a que no todos los bienes preciosos enviados a Tenochtitlan eran depositados como ofrendas en el Templo Mayor, ya que pudieron haber sido empleados para otros fines, como su utilización por parte de las élites y de los gobernantes mexicas, ya que las insignias de turquesa servían para expresar su poder y status (Olko 2005). Además, uno de los sartales pertenece a la etapa II (1375-1428 d.C.), cuando los mexicas todavía estaban bajo el dominio de Azcapotzalco. En el caso de los discos, las fuentes señalan que eran los huastecos quienes los tributaban (Figura 23a-b), aunque no hay evidencias de este tipo de objetos en aquella región, por lo cual debieron adquirirlos con otros grupos (Melgar 2014).

En cuanto al análisis de las representaciones gráficas de los materiales azules tributados, la mayoría asume que son turquesas, pero casi nadie aborda la discrepancia que presentan las glosas de Quiyauhteopan y Yohualtepec que aluden a una resina que tiñe de azul y a plantas en vez del mineral de turquesa, como sí aparece en los objetos de Tochpan (Saville 1922: 24; Rojas 1995: 658). En el caso de matlauac xiuitl, una cazuela con turquesas que tributaba la provincia de Quiyauhteopan (Figura 23c-d), para varios autores se trata de una corrupción de la palabra matlaltic (Saville 1922: 24; Mohar 1987: 207), aunque para Rojas (1995: 658) falta la «l» al final para poder justificarla. Como alternativa, nosotros consideramos que la mención de la resina pudiera deberse a la confusión en la lectura e interpretación de la glosa en náhuatl, matlauac xiuitl con matlalxiuitl, la planta de la que se obtenía resina para pintar de color azul (Siméon 2010: 260). Basándonos en ello, podemos inferir que quien glosó al español el documento no tuvo cuidado en la identificación correcta o 

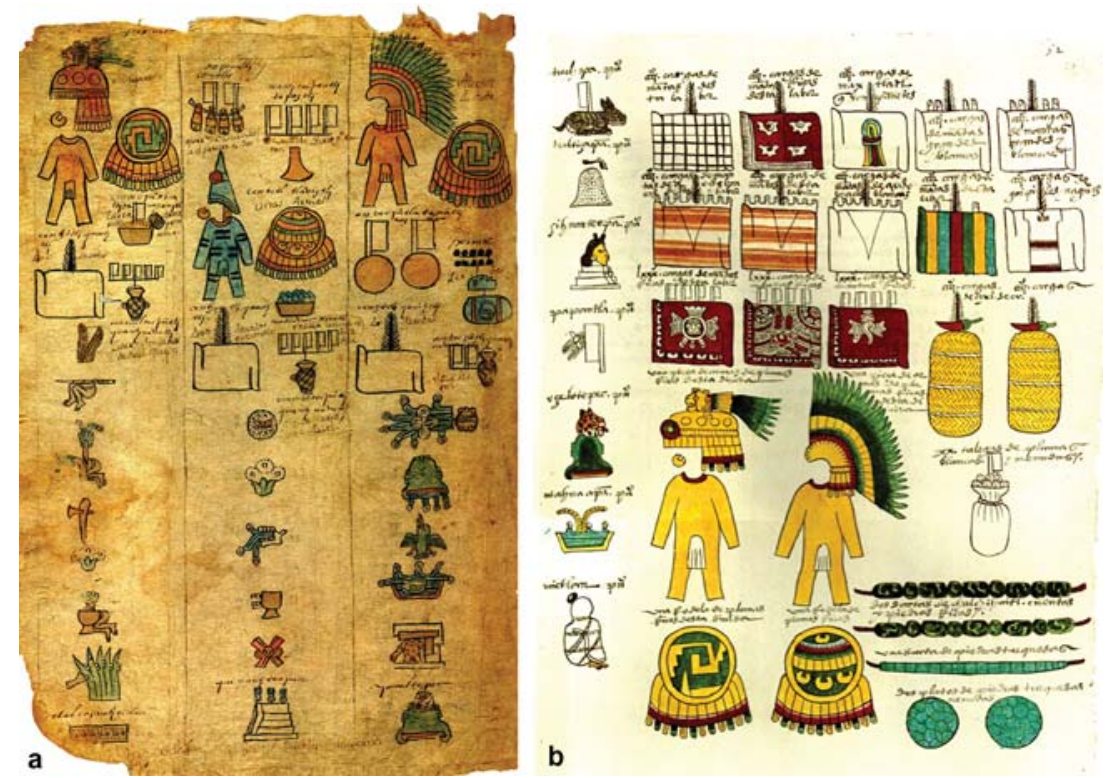

Figura 22. Provincias tributarias de objetos de turquesa a Tenochtitlan: Quiyauhteopan y Yohualtepec en la Matrícula de Tributos (a) y Tochpan en el Códice Mendoza (b).
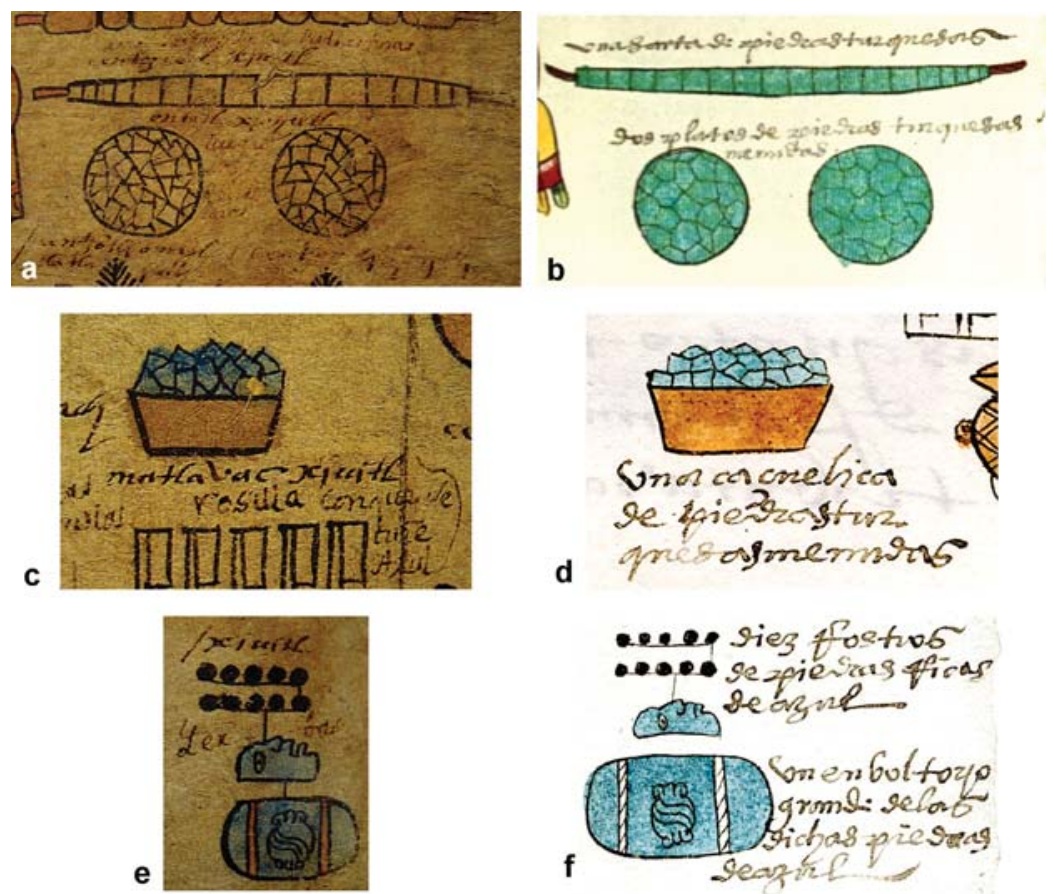

Figura 23. Comparación de los bienes tributados de turquesa ilustrados en la Matrícula de Tributos y el Códice Mendoza: un sartal y dos discos de Tochpan (a-b), una cazuela con turquesas de Quiyauhteopan (c-d) y un paquete con diez máscaras de mosaico de turquesa de Yohualtepec (e-f). 
coherencia entre el material representado y su nomenclatura en náhuatl con la traducción al español. Algo parecido sucede en la glosa xiuitl, que acompaña a las máscaras y al fardo que tributaba Yohualtepec en la Matrícula de Tributos (Figura 23e-f). $\mathrm{Su}$ traducción como «yerbas» en el Códice Mendocino se debe a que el amanuense no tomó en cuenta la representación gráfica del material al poner esta acepción de la palabra en lugar de turquesa (Melgar 2014).

\section{Los mosaicos de turquesa de Tenochtitlan y la tradición Mixteca-Puebla}

Debido a la presencia de dos mosaicos del Templo Mayor con representaciones de personajes similares a los de la tradición Mixteca-Puebla, los comparamos con piezas halladas en contexto arqueológico, como los mosaicos de la Cueva Chevé y la Tumba 1 de Zaachila, entre otros. De ello podemos destacar lo siguiente (Figura 24): los artesanos mixtecos combinaron la turquesa con otros materiales, sobre todo concha, mientras que en el Templo Mayor solamente se utilizó turquesa. Los personajes en los mosaicos mixtecos presentan la totalidad del rostro hecho en una sola pieza, mientas que en Tenochtitlan están conformados por dos piezas, a veces de distinto color/tonalidad de manera intencional, como si estuvieran indicando pintura facial, dividiendo el rostro transversalmente. Los brazos y piernas en las piezas mixtecas aparecen flexionados y están hechos por una o dos piezas geométricas curvas, mientras que en los de la Ofrenda 99 emplean varias teselas rectangulares para representar ese movimiento. Los troncos en las piezas mixtecas aparecen hechos en una sola pieza más o menos rectangular de gran tamaño, mientras que en el disco de Tenochtitlan están conformados por varias teselas. En cuanto a los personajes representados, aunque comparten convenciones iconográficas, en los mixtecos se aprecia a Ehécatl-Quetzalcóatl mientras que en el del Templo Mayor están Mixcóatl, Tlahuizcalpantecuhtli y Huitzilopochtli. Todas estas diferencias permiten inferir que las piezas tenochcas conforman una variante de la tradición Mixteca-Puebla.

\section{Conclusiones}

Como hemos podido apreciar, el estudio integral de los objetos de turquesa del Templo Mayor ha ofrecido nuevos datos sobre el origen, variedad y simbolismo de estos
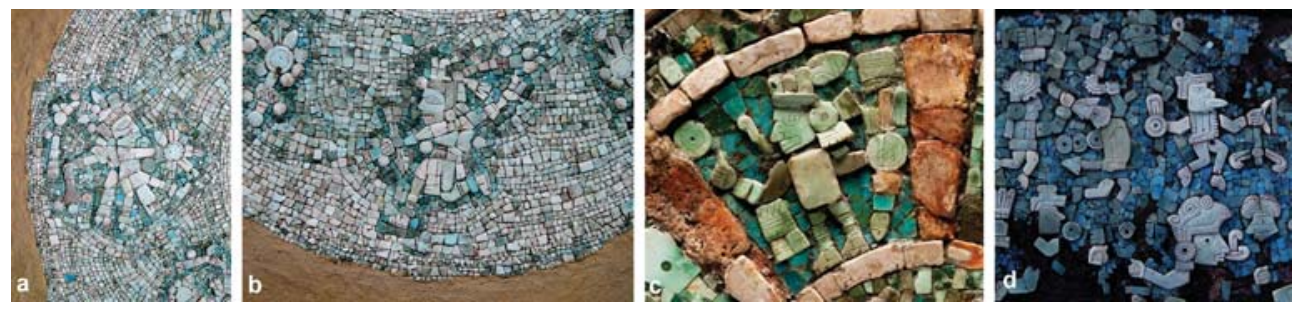

Figura 24. Comparación en el armado de personajes de mosaicos de turquesa del Templo Mayor de Tenochtitlan (a-b) con los de Zaachila (c) y la Cueva Chevé (d) en Oaxaca. (Fotografías de Emiliano Melgar). 
minerales azules, así como el análisis detallado de la tecnología empleada en la confección de estos ornamentos de algunas divinidades, en especial del dios del fuego Xiuhtecuhtli, y como emblema de poder y prestigio de la élite tenochca.

Esta rareza del material, por su carácter exótico, y la dificultad para adquirirlo, así como la calidad excepcional en su manufactura, le confirieron a la turquesa los atributos que permiten clasificarla como un bien de prestigio. Por este gran aprecio se convirtió en un elemento de suma importancia en la economía política mexica, ya que se reguló su flujo y consumo para ser empleada en el culto religioso como parte de los atavíos e insignias de las divinidades, como adorno que enfatizaba el estatus de las élites y como emblema del poder real y la sucesión política de los gobernantes.

Este interés en las turquesas de zonas desérticas norteñas también pudiera estar relacionado con cierta oposición simbólica que tienen con las piedras verdes, de origen sureño en valles tropicales de ríos caudalosos. Al respecto, las turquesas aluden al fuego, el linaje, la realeza, el cometa y el año, aunque también tienen la raíz para indicar hierbas y hojas. Por su parte, las piedras verdes se vinculan con la lluvia, las deidades pluviales, la fertilidad y las corrientes de agua. Por ello la piedra azul más valorada fue la turquesa de los dioses llamada teoxíhuitl, la cual era traída de lejos por los teochichimecas, grupos de cazadores que habitaban en los desiertos, montes y cuevas septentrionales.

Aunque los mexicas también tuvieron acceso a este material a través del tributo de cazuelas con turquesas, máscaras, collares y discos de mosaico que hacían tres provincias (Quiyauhteopan, Yohualtepec y Tochpan), prácticamente ninguno de esos objetos se ha recuperado en las ofrendas, salvo un par de sartales y dos discos. Su escasez en las ofrendas puede deberse a que no todos los bienes tributados eran depositados como ofrendas en el Templo Mayor. Quizás las élites y los gobernantes mexicas usaron estos materiales con otros fines, como las insignias de turquesa que servían para expresar su poder y estatus.

En cuanto a su filiación cultural, el estudio tecnológico permitió detectar tres patrones de manufactura, dos foráneos (uno relacionado con el Noroeste de México/ Suroeste de los Estados Unidos) y uno local (que comparte los cánones del estilo imperial tenochca).

Para finalizar, este tipo de estudios comparativos a nivel mineralógico, morfológico, simbólico y tecnológico son necesarios para poder identificar con mayor precisión los lugares de obtención, elaboración y distribución de estos objetos lapidarios, al tiempo que permiten profundizar en las formas en que los grupos prehispánicos transformaban estas materias primas para dotarlas de significado.

\footnotetext{
AgRadeCimientos: Esta investigación no hubiera sido posible sin el apoyo del personal de la Bodega de Resguardo de Bienes Culturales del Museo del Templo Mayor y su directora, la Mtra. Patricia Ledesma y al Dr. Adrián Velázquez en el inicio de esta metodología de estudio experimental. También al apoyo del Mtro. Mario Monroy en los análisis de MEB-EDS del INAH y a la Mtra. Cristina Zorrilla con el Micro-Raman del IF-UNAM, así como la asesoría en Códices de la Dra. María Castañeda, al Dr. Emiliano Gallaga en introducirme a la arqueología norteña, a la Dra. Joan Mathien y Dra. Wendy Bustard por las facilidades para revisar turquesas de Chaco Canyon y al Dr. Saul Hedquist por el acceso a turquesas de Arizona. Así mismo fue importante la participación de los integrantes del taller de lapidaria en la ejecución de experimentos y a la Dra. Reyna Solís en el apoyo para terminar este estudio.
} 


\section{Referencias}

Castillo Bernal, Stephen y Bertina Olmedo Vera. 2016. El cosmos y sus espejos: el tezcacuitlapilli entre los toltecas y los mexicas. México: Instituto Nacional de Antropología e Historia.

Cobos, Rafael. 1998. «Chichen Itzá y el Clásico terminal en las Tierras Bajas Mayas», en XI Simposio de Investigaciones Arqueológicas en Guatemala, 1997. Juan Pedro Laporte y Héctor Escobedo, eds., pp. 915-930. Guatemala: Museo Nacional de Antropología y Etnología.

Codex Mendoza. 1992. Codex Mendoza. Berkeley: University of California Press.

Códice Borbónico. 1991. Códice Borbónico. México: Fondo de Cultura Económica.

Códice Ixtlilxóchitl. 1996. Códice Ixtlilxóchitl. México: Fondo de Cultura Económica.

Códice Mendocino. 1979. Códice Mendocino o Colección de Mendoza. México: San Ángel Ediciones.

Códice Telleriano Remensis. 1964. Códice Telleriano Remensis. México: Secretaría de Hacienda y Crédito Público.

Domenici, Davide. 2016. «Máscaras, escudos y tablas con mosaicos de turquesa en Oaxaca y Puebla». Arqueología Mexicana 141: 44-49.

Gallaga Murrieta, Emiliano. 2017. Una visita al Museo. México: Escuela de Antropología e Historia del Norte de México e Instituto Nacional de Antropología e Historia.

Gallaga Murrieta, Emiliano y Marc G. Blainey, eds. 2016. Manufactured Light: Mirrors in the Mesoamerican Realm. Boulder: University Press of Colorado.

Gallaga Murrieta Emiliano y Emiliano Ricardo Melgar Tísoc. 2016. «Las turquesas del Valle de Onavas: análisis y resultados», en Sociedades mineras en América Latina, México, Abel Rodríguez, coord., tomo I, pp. 110-127. México: Secretaría de Cultura, Instituto Nacional de Antropología e Historia y Escuela de Antropología e Historia del Norte de México.

Hermann Lejarazu, Manuel. 2009. «La serpiente de fuego o yahui en la Mixteca prehispánica: iconografía y significado». Anales del Museo de América 17: 64-77.

Izeki, Mutsumi. 2008. Conceptualization of Xihuitl': History, Environment and Cultural Dynamics in Postclassic Mexica Cognition. BAR International Series 1863. Oxford: ArcheoPress.

López Luján, Leonardo. 2006. La Casa de las Águilas. Un ejemplo de la arquitectura religiosa de Tenochtitlan, 2 volúmenes. México: Mesoamerican Archive and Research Project, Harvard University-Conaculta-Instituto Nacional de Antropología e HistoriaFondo de Cultura Económica.

Matrícula de tributos. 1991. Matrícula de tributos. Nuevos estudios. México: Secretaría de Hacienda y Crédito Público.

Melgar Tísoc, Emiliano Ricardo. 2014. Comercio, tributo y producción de las turquesas del Templo Mayor de Tenochtitlan. Tesis doctoral. México: Universidad Nacional Autónoma de México.

Mohar Betancourt, Luz María. 1987. El tributo mexica en el siglo XVI: análisis de dos fuentes pictográficas. México: Centro de Investigaciones y Estudios Superiores en Antropología Social.

Molina, Fray Alonso de. 1944. Vocabulario en lengua castellana y mexicana. Madrid: Cultura Hispánica.

Newell, Gillian y Emiliano Gallaga Murrieta, eds. 2004 . Surveying the Archaeology of Northwest México. Salt Lake City: University of Utah Press. 
Noguez, Xavier. 1975. «La diadema de turquesa (xiuhuitzolli) y las alianzas de señoríos prehispánicos. Acercamiento iconográfico», en XIII Mesa Redonda de la Sociedad Mexicana de Antropología: balance y perspectiva de la antropología de Mesoamérica y del Norte de México, pp. 83-94. México: Sociedad Mexicana de Antropología.

Olko, Justyna. 2005. Turquoise Diadems and Staffs of Office. Elite Costume and Insignia of Power in Aztec and Early Colonial Mexico. Varsovia: Universidad de Varsovia.

Rojas, José Luis de. 1995. «Los libros pictográficos de tributos: Códice Mendoza y Matrícula de Tributos». Estudios de Historia Social y Económica de América 12: 651-662.

Sahagún, fray Bernardino de. 1979. Códice Florentino. El manuscrito 218-220 de la colección Palatina de la Biblioteca Medicea Laurenziana, 3 volúmenes. México: Giunti Barbéra - Archivo General de la Nación.

-1993. Primeros memoriales. Edición facsimilar. Norman - Madrid: University of Oklahoma Press - Real Academia de la Historia.

- 2006. Historia general de las cosas de Nueva España. México: Porrúa.

Saville, Marshall H. 1922. Turquoise Mosaic Art in Ancient Mexico. Nueva York: Museum of the American Indian - Heye Foundation.

Schávelzon, Daniel. 1980. El complejo arqueológico Mixteca-Puebla. Notas para una redefinición cultural. México: Universidad Nacional Autónoma de México.

Siméon, Rémi. 2010. Diccionario de la lengua náhuatl o mexicana, 19 reimpr. México: Siglo XXI.

Taube, Karl A. 2000. «The Turquoise Hearth. Fire, Self-Sacrifice, and the Central Mexican Cult of War», en Mesoamerica's Classic heritage: From Teotihuacan to the Aztecs, David Carrasco, Lindsay Jones y Scott Sessions, eds., pp. 269-340. Boulder: University Press of Colorado.

- 2012. "The Symbolism of Turquoise in Ancient Mesoamerica», en Turquoise in Mexico and North America, Jonathan C.H. King, Max Carocci, Caroline Cartwright, Colin McEwan y Rebecca Stacey, eds., pp. 117-134. Londres: Archetype - The British Museum.

Torquemada, fray Juan de. 1975. Monarquía indiana. De los veinte y un libros rituales y monarquía indiana, con el origen y guerras de los indios occidentales, de sus poblazones, descubrimiento, conquista, conversión y otras cosas maravillosas de la mesma tierra, 3 vols. México: Universidad Nacional Autónoma de México.

Velázquez Castro, Adrián. 1999. Tipología de los objetos de concha del Templo Mayor de Tenochtitlan. México: Instituto Nacional de Antropología e Historia.

Velázquez Castro, Adrián, María Eugenia Marín Benito, Emiliano Ricardo Melgar Tísoc y Reyna Beatriz Solís Ciriaco. 2012. «The turquoise Disk from Offering 99 at the Templo Mayor in Tenochtitlan», en Turquoise in Mexico and North America, Jonathan C.H. King, Max Carocci, Caroline Cartwright, Colin McEwan y Rebecca Stacey, eds., pp. 75-87. Londres: Archetype - The British Museum.

Weigand, Phil C. 1993. Evolución de una civilización prehispánica: arqueología de Jalisco, Nayarit y Zacatecas. Zamora: El Colegio de Michoacán.

—. 1997. «Minería prehispánica: la turquesa». Arqueología Mexicana 6: 26-33.

Willey, Gordon R. y Philip Phillips. 1954. Method and Theory in American Archaeology. Chicago: The University of Chicago Press. 